\title{
Preventive effects of bone marrow-derived mesenchymal stem cell transplantation in a D-galactose-induced brain aging in rats
}

\author{
G. El-Akabawy'1,2,3, K. Aabed ${ }^{4}$, L.A. Rashed ${ }^{5}$, S.N. Amin ${ }^{6,7}$, I. AlSaati², M. Al-Fayez ${ }^{8}$ \\ ${ }^{1}$ Department of Basic Medical Sciences, College of Medicine, Ajman University, Ajman, United Arab Emirates \\ ${ }^{2}$ Department of Basic Sciences, College of Medicine, Princess Nourah bint Abdulrahman University, Riyadh, Saudi Arabia \\ ${ }^{3}$ Department of Anatomy and Embryology, Faculty of Medicine, Menoufia University, Menoufia, Egypt \\ ${ }^{4}$ Department of Biology, College of Science, Princess Nourah bint Abdulrahman University, Riyadh, Saudi Arabia \\ ${ }^{5}$ Department of Medical Biochemistry, Faculty of Medicine, Cairo University, Cairo, Egypt \\ ${ }^{6}$ Department of Medical Physiology, Faculty of Medicine, Cairo University, Cairo, Egypt \\ ${ }^{7}$ Department of Basic Medical Sciences, Faculty of Medicine, The Hashemite University, Zarqaa, Jordan \\ ${ }^{8}$ Department of Anatomy, College of Medicine, King Saud University, Riyadh, Saudi Arabia
}

[Received: 27 April 2021; Accepted: 17 July 2021; Early publication date: 3 August 2021]

Background: Aging is a complex process accompanied by numerous morphological, functional, and metabolic impairments in the brain, and a critical risk factor involved in the increasing incidence of neurodegenerative diseases. Few studies have evaluated the efficacy of different sources of mesenchymal stem cells (MSCS) in ameliorating the early morphological and functional alterations in the aging brain. This study, for the first time, evaluated the potential efficacy of intravenous injection of bone marrow-derived mesenchymal stem cells (BMMSCs) in a D-galactose-induced rat model of brain aging.

Materials and methods: BMMSCs $\left(1 \times 10^{6}\right)$ were intravenously injected into brain aging model rats once every 2 weeks for 8 weeks.

Results: The transplanted cells survived and migrated to the brain, and differentiated into astrocytes and neurons, including choline acetyltransferase neurons. BMMSC transplantation improved locomotor activity and cognitive functions, restored cholinergic system function, protected atrophic cholinergic neurons in the basal forebrain, induced antioxidative effects and restored neurotrophic factors, and modulated hippocampal synaptic plasticity by upregulating PSD95 and Egr1 expression.

Conclusions: Our findings demonstrated the efficacy of BMMSC injection in an aging rat model and suggest that these cells may be developed into an effective cell therapy for the aging brain. (Folia Morphol 2022; 81, 3: 632-649)

Key words: bone marrow-mesenchymal stem cells, D-galactose, rat, brain

\section{INTRODUCTION}

Aging is a progressive, complex process accompanied with morphological, functional, and metabolic alterations in the brain, and a critical risk factor in- volved in the escalating prevalence of neurodegenerative, age-related diseases, such as Alzheimer's disease (AD) and Parkinson's disease (PD) [19, 34, 63, 71, 94]. A distinction can be made between the gradual

Address for correspondence: G.F.A. El-Akabawy, PhD, Current address: Princess Nourah bint Abdulrahman University, College of Medicine, Riyadh, Saudi Arabia, tel: 00966554352501, e-mail: gfelakabawy@pnu.edu.sa; Permanent address: Menoufia University, Faculty of Medicine, Menoufia, Egypt, e-mail: Gehanakabawy@gmail.com

This article is available in open access under Creative Common Attribution-Non-Commercial-No Derivatives 4.0 International (CC BY-NC-ND 4.0) license, allowing to download articles and share them with others as long as they credit the authors and the publisher, but without permission to change them in any way or use them commercially. 
decline in the structural and functional brain status in the non-diseased stage (primary or normal aging) and the progressive structural and functional loss resulting from age-related diseases (secondary aging) [43].

Cognitive functions controlled by the hippocampus and prefrontal cortex are greatly affected by normal aging. Both brain regions experience cellular and synaptic changes that are related to a deterioration in cognitive activities $[8,11,35,52,53]$. The brain cells the most vulnerable to the deleterious consequences of aging are cholinergic neurons. During normal aging, the cholinergic system of the basal forebrain undergoes moderate neurodegenerative alterations, while in $A D$, it shows severe deteriorations. Aging and $A D$ are associated with a progressive degeneration of the cholinergic neurons, characterised by a decline in choline acetyltransferase (ChAT) activity, followed by a reduction in acetylcholine $(A C h)$ release $[28,31,33$, $46,48,49,72,82]$. The levels of neurotrophic factors, such as brain-derived neurotrophic factor (BDNF) and nerve growth factor (NGF), are also remarkably decreased in aging and $A D$, which can be linked to cognitive impairments $[15,50,83]$. In addition, it is well-established that aging is associated with declines in neurotransmitter and receptor levels, reduced synapse numbers, and increased oxidative stress, leading to the marked neurodegenerative status associated with age-related diseases $[29,38,43,47,75,94]$.

The structural and functional impairments associated with aging are accelerated in the presence of age-related diseases; hence, therapies that ameliorate primary and/or secondary aging are a principal target in aging research $[42,43]$. Stem cell therapy has proven its efficacy in both $A D$ and $P D$ in pre-clinical and clinical studies. Among the different types of stem cells, mesenchymal stem cells (MSCs) are the most promising because they can differentiate toward the neuronal fate, release neurotrophic factors, and enhance endogenous brain repair. In addition, they have immunomodulatory, neuroprotective, angiogenic, and chemotactic properties $[4,10]$. In rodent $A D$ models, MSC transplantation has been demonstrated to down-regulate $A \beta$ deposits, enhance neurogenesis and neuronal differentiation, and alleviate spatial learning and memory deficits. Further, MSCs have anti-inflammatory and immunomodulatory effects $[25,41,54,56,58-60,68,85,90,92,95]$. Based on these and other studies, in 2015, the Food and Drug Administration (FDA) approved the first phase 2A clinical trial of MSCs for AD treatment, and sim- ilar trials were designed in Europe and Asia [36]. Recently, the FDA approved a phase 1/2 trial of autologous, adipose-derived MSCs for the treatment of AD (NCT04228666).

Most studies evaluating the efficacy of stem cells have been conducted in preclinical animal models or in patients with $A D$ and $P D$, in which structural and functional brain capacities are extensively deteriorated. It could be postulated that early intervention to encounter the neuropathological alterations during primary aging would prevent or at least slow down the pathological processes leading to secondary aging, and hence reduce the incidence of age-related diseases $[3,42,43,64,75,94]$. Notably, studies investigating the administration of human (h)MSCs derived from bone marrow or adipose tissue in mouse models of hind limb ischaemia have reported controversial outcomes regarding which type of MSCs is the most effective $[13,40]$. Proof for the superiority of specific MSCs source for the treatment of neurodegenerative disorders is lacking. Since the potential differences between MSCs isolated from different sources may result in diverse clinical effects, studies to decide the most efficacious MSC types for each clinical condition are needed [84].

Few studies have evaluated the efficacy of MSC transplantation in animal models of aging [17, 39, $61,74,91]$. Therefore, we sought to assess, for the first time, the potential beneficial effect of systemic transplantation of bone marrow (BM)-derived MSCs (BMMSCs) on the cortex, hippocampus, and forebrain in a D-galactose-induced rat model of brain aging in order to evaluate their potential as a preventive approach for age-related neurodegeneration.

\section{MATERIALS AND METHODS}

\section{Animals}

Thirty male Sprague Dawley rats (8 weeks old, 180-200 g) were purchased from the Theodor Bilharz Research Institute, Imbaba, Egypt and were kept in the animal house of the Faculty of Medicine, Menoufia University, Egypt. The rats were housed in standard polycarbonate cages with 2 rats in cage under standard laboratory conditions $\left(22 \pm 5^{\circ} \mathrm{C}, 60 \pm 5 \%\right.$ humidity, and a 12-h/12-h light/dark cycle). Standard laboratory chow and tap water were available $a d$ libitum. All experimental procedures involving animals were approved by Institutional Review Board of Princess Nourah bint Abdulrahman University, KSA [IRB\# 18-0165] and Institutional Review Board 
of Menoufia University, Faculty of Medicine, Egypt [IRB\# 191219ANAT] and were conducted in accordance with the guidelines on the ethical use of animals in the European Community Council Directive 2010/63/EU.

\section{BMMSC isolation and culture}

Bone marrow-derived MSCs were obtained from 6- to 8-week-old male Sprague Dawley rats as previously reported [65]. Briefly, BM plugs were collected from the femurs and tibias of the rats using a 23-gauge needle and centrifuged for $5 \mathrm{~min}$ at room temperature (RT) at 1,800 rpm. The pelleted cells were then resuspended in Dulbecco's modified Eagle's medium (DMEM, Gibco, Carlsbad, CA, USA) containing $10 \%$ foetal bovine serum (FBS) (Gibco) and 1\% penicillin-streptomycin (Gibco) and seeded at a density of $1 \times 10^{6}$ cells $/ \mathrm{cm}$ in $25 \mathrm{~cm}^{2}$ cell culture flasks. The cells were incubated at $37^{\circ} \mathrm{C}$ in a humidified atmosphere with $5 \% \mathrm{CO}_{2}$. A complete medium change was performed every 3-4 days to remove non-adherent hematopoietic cells. When the confluence of the cells reached $70 \%$, they were harvested for 2-5 min using $0.25 \%$ Trypsin-EDTA (Sigma-Aldrich, St. Louis, MO, USA), then neutralised with complete medium and centrifuged at $500 \times \mathrm{g}$ for $5 \mathrm{~min}$. Cell pellets were resuspended in complete medium. The viability of the cells was assessed by adding equal volumes of the cell suspension and $0.4 \%$ Trypan blue (Gibco), and loading $10 \mu \mathrm{L}$ of the stained suspension into each chamber of a haemocytometer. Viable and dead cells were calculated within $5 \mathrm{~min}$ of sample preparation. Cells with greater than $90 \%$ viability were subcultured at a 1:3 (passage 1). Cells were used at passage 4.

\section{Flow cytometry}

Cells were resuspended in staining buffer (2\% FBS/PBS) and surface-stained with FITC-conjugated mouse anti-rat CD44 (BioLegend, UK), FITCH-conjugated mouse anti-rat CD90 (BD Pharmingen, USA), or PE-conjugated rabbit anti-rat CD34 (Abcam, UK) at $4^{\circ} \mathrm{C}$ for $30 \mathrm{~min}$. Isotype-matched antibodies served as controls. The cells were analysed using an EPICS XL flow cytometer (Beckman Coulter).

\section{Experimental design}

The rats were randomly assigned to three groups: control, D-galactose (D-gal)-treated, and D-gal + BMMSCs-treated ( $n=10$ in each group). The sample size was calculated using the $\mathrm{G}$ Power software. Rats in the D-gal- and D-gal + BMMSCs-treated groups received a subcutaneous injection of D-gal $(300 \mathrm{mg} /$ $/ \mathrm{kg}$, Sigma-Aldrich, St. Louis, MO, USA) every day for 8 weeks. Rats in the D-gal + BMMSCs group were intravenously administered $1 \times 10^{6} \mathrm{BMMSC}$ labelled with the membrane-bound fluorescent marker PKH26 (Sigma-Aldrich) once every 2 weeks.

\section{Behavioural tests}

All animals were acclimatised 1 week following arrival to behavioural testing. Tests were conducted 1 week after the last transplantation. Test sessions were conducted between 2 PM and 5 PM. Two observers were present throughout each session and were blind to experimental condition.

\section{Open-field test}

The open-field test allows simultaneous evaluations of exploration, locomotion, and anxiety. A box of $1 \mathrm{~m} \times 1 \mathrm{~m}$ and $50 \mathrm{~cm}$ in height was made of wood. The floor of the box was divided into equally areas. Each rat was positioned in the centre of the open field arena and the rearing frequency, number of crossing the lines (with both forepaws), and number and duration of central square entries (with both forepaws) were recorded using a video camera installed $2.5 \mathrm{~m}$ above the box for $5 \mathrm{~min}$. The box was placed in a noiseless room with controlled illumination.

\section{Y-maze test}

The Y-maze task was used to evaluate spatial working memory. A Y-maze with three equal-sized wooden arms $(60 \mathrm{~cm}, 12 \mathrm{~cm}, 25 \mathrm{~cm})$ was designed. Each rat was placed in the centre of the maze and permitted to explore the three arms for $8 \mathrm{~min}$. A correct choice was scored when any three successive choices of three different arms were entered. An alternation score was obtained as the total number of alternations divided by the total number of choices minus 2 .

\section{Measurement of body weight and the brain index}

The general condition of the rats, including behavioural activity and glossiness and colour of the hair coat, was observed daily. Body weights were assessed weekly. At the end the experiment, the rats were anaesthetised through intraperitoneal injection of ketamine $(90 \mathrm{mg} /$ $/ \mathrm{kg}$ ) and xylazine $(15 \mathrm{mg} / \mathrm{kg})$ and decapitated. Brains were immediately harvested from all rats and weighed. Brain indices were calculated in the following manner: brain tissue weight (mg)/final body weight $(\mathrm{g})$. 
Table I. List of primers used in quantitative reverse-transcription polymerase chain reaction

\begin{tabular}{|c|c|c|}
\hline Gene name & Gene accession & Primer sequence forward/reverse $5^{\prime} \rightarrow 3^{\prime}$ \\
\hline ChT1 & NM_053521 & $\begin{array}{l}\text { CAAGACCAAGGAGGAAGCAG } \\
\text { GCAAACATGGAACTTGCTGA }\end{array}$ \\
\hline ChAT & XM_224626 & $\begin{array}{l}\text { TGAACGCCTGCCTCCATTCGGC CTGCTGA } \\
\text { GTGCCATCTCGGCCACCACG AACTGCA }\end{array}$ \\
\hline VAChT & NM_031663 & $\begin{array}{l}\text { GCCACATCGTTCACTCTCTTG } \\
\text { CGGTTCATCAAGCAACACATC }\end{array}$ \\
\hline M1AChR & NM_080773 & $\begin{array}{l}\text { CCTACAGCTGGAAGGAAGAA } \\
\text { GCCTGTGCTTCAGAATCTAC }\end{array}$ \\
\hline $\mathrm{nAChR} \alpha 5$ & NM_017078 & $\begin{array}{l}\text { TGGAACACCTGAGCGACAAG } \\
\text { CGTGACAGTGCCGTTGTACC }\end{array}$ \\
\hline $\mathrm{nAChR} \beta 2$ & NM_019297 & $\begin{array}{l}\text { CGGGAAGCAGTGGATGGCGTA } \\
\text { GTCCTCCCTCACACTCTGGTCATCA }\end{array}$ \\
\hline Egr1 & NM_012551 & $\begin{array}{l}\text { AAGACACCCCCCCATGAAC } \\
\text { CTCATCCGAGCGAGAAAAGC }\end{array}$ \\
\hline BDNF & NM_012842 & $\begin{array}{l}\text { TGTCCGAGGTGGTAGTACTTCATC } \\
\text { CATGCAACCGAAGTATGAAATAACC }\end{array}$ \\
\hline VEGF & AF062644 & $\begin{array}{l}\text { GAGGAAAGGGAAAGGGTCAAAA } \\
\text { CACAGTGAACGCTCCAGGATT }\end{array}$ \\
\hline NGF & XM_227525 & $\begin{array}{l}\text { TGC ATA GCG TAA TGT CCA TGT TG } \\
\text { CTG TGT CAA GGG AAT GCT GAA }\end{array}$ \\
\hline BETA-ACTIN & NM_031144 & $\begin{array}{l}\text { AПTTGGCACCACACTTCTACA } \\
\text { TCACGCACGATTTCCCTCTCAG }\end{array}$ \\
\hline
\end{tabular}

Abbreviations - see text.

\section{Assessment of oxidative stress and antioxidants indices}

A spectrophotometer was used to determine the levels of malondialdehyde (MDA) and glutathione (GSH) in brain tissue. To assess the extent of lipid peroxidation, rats' cortices and hippocampi (100 mg) were homogenised in $1 \mathrm{~mL}$ of phosphate buffer solution (PBS; $\mathrm{pH} 7.0$ ) and the MDA concentration was measured [87]. The homogenates were centrifuged after being mixed with trichloroacetic acid (TCA; $20 \%$ ) at $5000 \mathrm{rpm}$ for $15 \mathrm{~min}$. The supernatants were treated with a $5 \%$ thiobarbituric acid (TBA) solution before being boiled in a water bath for $10 \mathrm{~min}$. The absorbance at $532 \mathrm{~nm}$ was determined, and the MDA concentration was estimated using the standard curve. The results were given in nanomoles ( $\mathrm{nmol}$ ) per milligram (mg) of protein.

Ellman's method [22] was used to assess GSH levels. A solution of dithiobis nitrobenzoate (DTNB) was added to cortices and hippocampi tissue homogenate and incubated for $1 \mathrm{~h}$. At $412 \mathrm{~nm}$, the absorbance was measured. The standard curve was used to measure the GSH concentration. The findings were expressed in micromoles $(\mathrm{mmol})$ per $\mathrm{mg}$ of protein.

\section{Quantitative reverse-transcription polymerase chain reaction (RT-qPCR)}

Total RNA was extracted from homogenised cortices and hippocampi of rats of each group using RNeasy Purification Reagent (Qiagen, Valencia, CA, USA) according to the manufacturer's protocol. RNA purity was assessed with a spectrophotometer; the wavelength absorption ratio $(260 / 280 \mathrm{~nm})$ was between 1.8 and 2.0 for all preparations. The RNA was reverse transcribed into cDNA using Superscript II (Gibco Life Technologies, Grand Island, NY, USA). qPCRs were run and analysed in a StepOneTM instrument with software version 3.1 (Applied Biosystems, Foster City, CA, USA). The reaction mixtures contained SYBR Green Master Mix (Applied Biosystems), a gene-specific primer pair (listed in Table 1), cDNA, and nuclease-free water. The cycling conditions were: $10 \mathrm{~min}$ at $95^{\circ} \mathrm{C}$ followed by 40 cycles of $15 \mathrm{~s}$ at $95^{\circ} \mathrm{C}$ and $60 \mathrm{~s}$ at $60^{\circ} \mathrm{C}$. The $A B I$ Prism sequence detection system software was used to analyse the data and quantification was achieved using the Sequence Detection Software v1.7 (PE Biosystems, Foster City, CA). Relative target gene expression was calculated using the comparative cycle threshold method [45]. All values were normalised to $\beta$-actin mRNA. 


\section{Immunohistochemical analysis}

For immunohistochemical staining, brains were fixed in $10 \%$ formalin and embedded in paraffin wax. Five-micrometre sections were deparaffinised, rehydrated, rinsed with PBS, and blocked in $0.1 \%$ $\mathrm{H}_{2} \mathrm{O}_{2}$ for 30 min to block endogenous peroxidase activity. The sections were incubated in $10 \%$ normal goat serum (blocking solution) at RT for $1 \mathrm{~h}$, then incubated with rabbit anti-polysynaptic density protein 95 (PSD95) primary antibody (1:500, Abcam, Cat. \#ab18258) at RT for 1 h. After rinsing with PBS, the sections were incubated with a biotinylated goat anti-rabbit secondary antibody $(1: 200$, Vector Labs, BA-1000, Peterborough, UK) at RT for $20 \mathrm{~min}$. The sections were treated with the enzyme conjugate streptavidin-horseradish peroxidase solution for $10 \mathrm{~min}$. Secondary antibody binding was detected using 3,3-diaminobenzoic acid dissolved in PBS with $\mathrm{H}_{2} \mathrm{O}_{2}(0.03 \%)$ added immediately before use. The sections were washed with PBS, counterstained with two drops $(100 \mu \mathrm{L})$ of haematoxylin, and rinsed in distilled water until they turned blue. Finally, the slides were dehydrated in an ascending graded ethanol series $(70 \%, 95 \%$, and $100 \%)$ for 5 min per concentration, cleared in xylene, mounted with Histomount, and covered with a coverslip.

For immunofluorescence staining, brains were dissected and fixed at $4^{\circ} \mathrm{C}$ for $24 \mathrm{~h}$, then cryoprotected in $30 \%$ sucrose at $4^{\circ} \mathrm{C}$. Serial sections $(40 \mu \mathrm{m})$ were cut by a cryostat and stored at $-20^{\circ} \mathrm{C}$ until use. The sections were incubated in $10 \%$ blocking solution (10\% normal goat serum in $0.3 \%$ Triton $\mathrm{X}-100$ in PBS) at RT for $1 \mathrm{~h}$, then incubated at $4^{\circ} \mathrm{C}$ overnight in the primary antibodies rabbit anti-Neun (1:1000, Abcam, Cat. \#ab177487), rabbit anti-GFAP (1:1000, Abcam, Cat. \#ab7260), or rabbit anti-ChAT (1:1000, Abcam, Cat. \#ab1778850). The sections were then rinsed in PBS and a secondary antibody was applied (1:500, Alexa-488, Cat. \#A-11034, Molecular Probes) at RT for $1 \mathrm{~h}$. Finally, the sections were rinsed in PBS and mounted in Fluoroshield Mounting Medium with DAPI (Abcam, Cat. \#ab104139).

\section{Quantitative histological assessments}

Five non-overlapping images per section were randomly captured from the cerebral cortex, whereas the entire basal forebrain and dentate gyral area were analysed for each brain section for each marker. Immunohistochemical images were captured using a Leica DML B2/11888111 microscope equipped with a Leica DFC450 camera, using the Leica C PLAN $4 \times / 0.10$ or $10 \times / 0.22$ objectives. Immunofluorescence images were captured using a Leica DM5500 $B / 11888817 / 12$ microscope equipped with a Leica DFC450C camera, using the Leica HI PLAN $10 \times / 0.25$ objective. For each image, the region of interest was the field of view at a magnification of $10 \times$. From at least three sections/rat, immunopositive cells were counted using the ImageJ software (National Institutes of Health, Bethesda, Maryland, US) by a manual approach using the plugin/cell counter tool [70] and then averaged per field for each rat. Calculated numbers for 10 animals/experimental group were considered for comparison and statistical analyses.

\section{Statistical analysis}

The data are expressed as the mean \pm standard error of mean (SEM). Normal distributions were evaluated using the D'Argostino and Pearson normality test, and data were analysed using one-way or two-way analysis of variance (ANOVA) followed by a post hoc Bonferroni test. $P<0.05$ was considered statistically significant. Statistical analyses were performed using GraphPad Prism 5.03 (GraphPad Software, San Diego, California, USA).

\section{RESULTS}

\section{Characterisation of BMMSCs}

After 10 days of culture, MSCs derived from the BM of Sprague-Dawley rats were spindle-shaped fibroblast-like cells. Cells from passage 4 were evaluated by flow cytometry for the expression of the markers CD90, CD44 (mesenchymal cell marker), CD34 (hematopoietic lineage marker). More than $90 \%$ of the cells were CD90+ and CD44+, whereas less than $10 \%$ were $\mathrm{CD} 34+$ (Fig. 1). These results indicated that the cells were mostly non-hematopoietic MSCs.

\section{BMMSC transplantation improves the physical characteristics, body weight, and brain indices}

Rats in the D-gal group exhibited signs of general aging in terms of physical appearance, i.e., reduced activity and rough, dull, yellow hair coat with hair loss, while rats in the transplanted group exhibited normal activity and smooth, glossy, brightly coloured hair coat, suggesting that BMMSC treatment had beneficial effects on D-gal-induced aging. In the current study, the body weights of the rats in the control, D-gal, and transplanted groups were not 

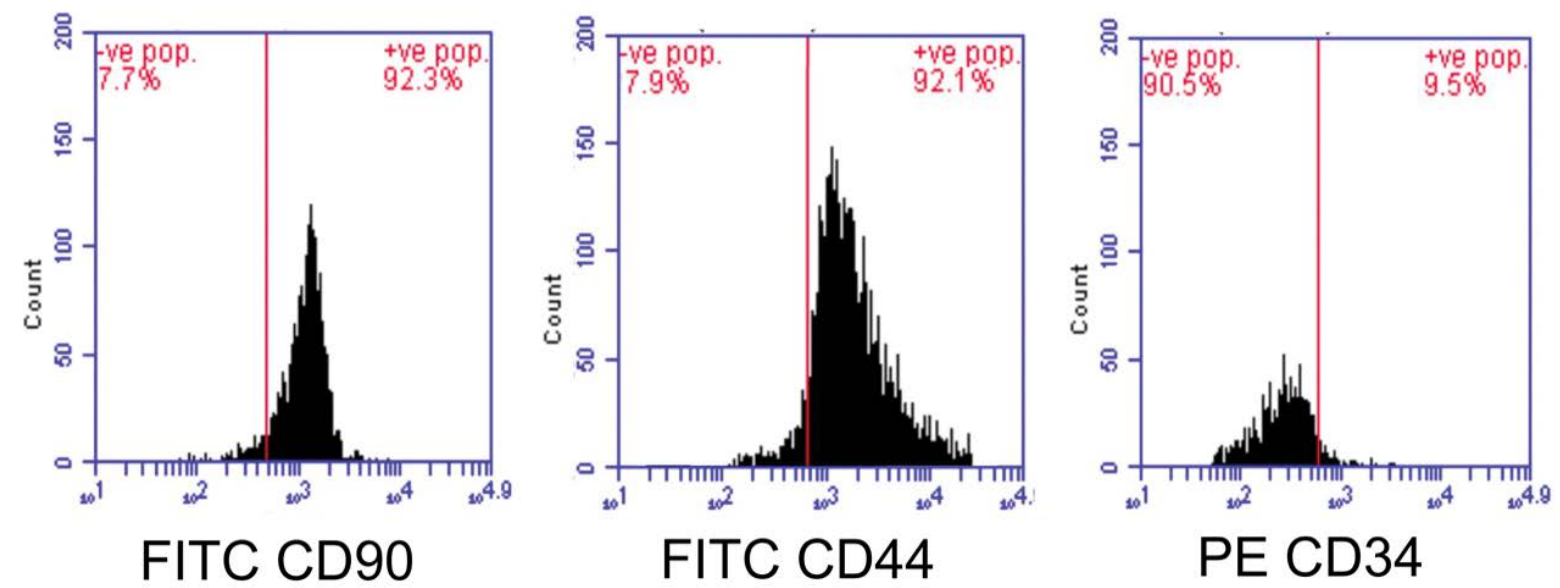

Figure 1. Characterisation of the bone marrow-derived mesenchymal stem cells (BMMSCs) population. The cell-surface phenotype of the BMMSCs was assessed by flow cytometry using antibodies against CD90, CD44, and CD34. In total, $92.3 \%$, and $92.1 \%$ of the cells expressed CD90 and CD44, respectively, whereas only $9.5 \%$ expressed CD34.
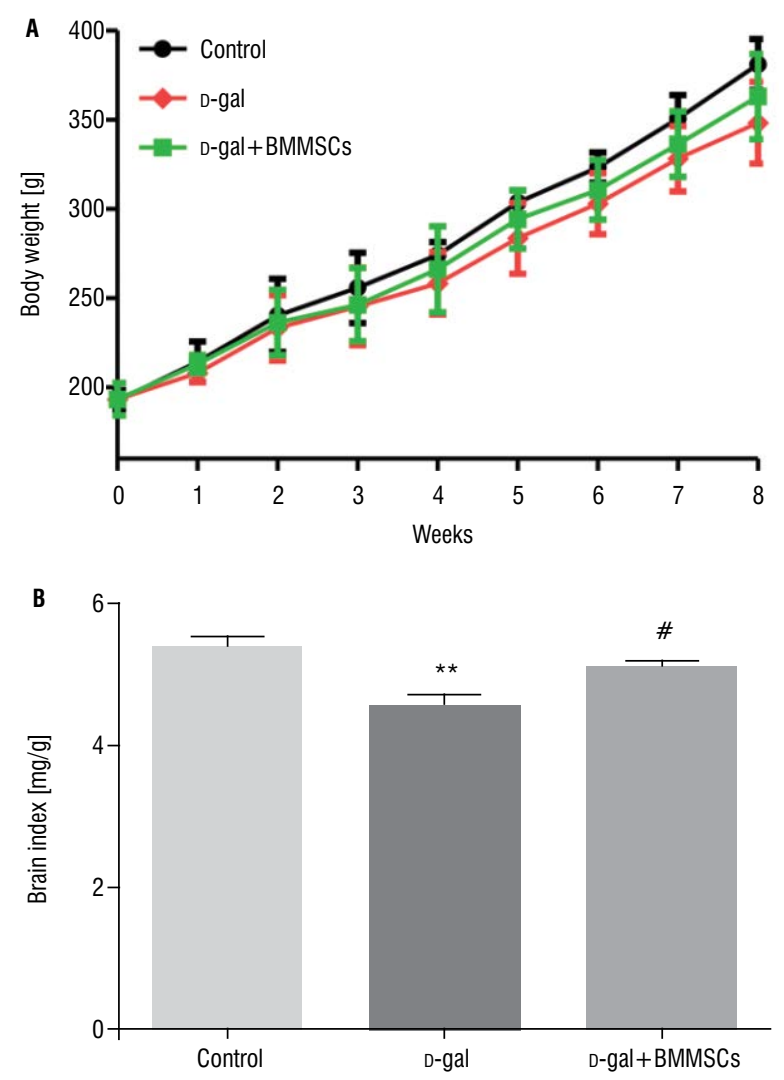

Figure 2. Body weight (A) and brain index (B) were evaluated in the control, aged (D-gal), and transplanted (D-gal + BMMSCs) rats; ${ }^{*} \mathrm{P}<0.001$ vs. control rats; ${ }^{\# P}<0.01$ vs. aged rats. Data are expressed as means \pm standard error of mean; $N=10$ /group; BMMSCs - bone marrow-derived mesenchymal stem cells.

significantly different. However, the brain index was significantly decreased in D-gal-treated rats compared with that in the control rats, whereas BMMSC treatment dramatically improved the brain index as compared with that in the aged rats (Fig. 2), indicating that transplanted cells prevented D-gal-induced brain atrophy.

BMMSCs improve spatial working memory, exploratory behaviour, and locomotion, and reduce anxiety in $D-g a l$ aging rats

Seven days after the last BMMSC injection, the reaction to a novel environment was evaluated using the open-field test. Aged rats showed significantly decreased exploratory behaviour and locomotion as indicated by significant declines in the rearing frequency and number of line crossings when compared to those in the control group (Fig. 3A, B). This was significantly improved by BMMSC injection as indicated by the significant increases in the rearing frequency and number of line crossings when compared to the values in the aging group (Fig. 3A, B). Parameters reflecting anxiety increased with aging. In the D-gal group, the frequency and duration of central square entries were significantly reduced as compared to those in the control group (Fig. 3C, D). BMMSC treatment ameliorated anxious behaviour and significantly increased the frequency and duration of central square entries as compared to those in the aged group (Fig. 3C, D).

The alternation score in the Y-maze task was dramatically decreased in the aged group when compared with the control group, which reflects impaired spatial working memory (Fig. 3E). BMMSC treatment significantly improved the spatial working memory 
A

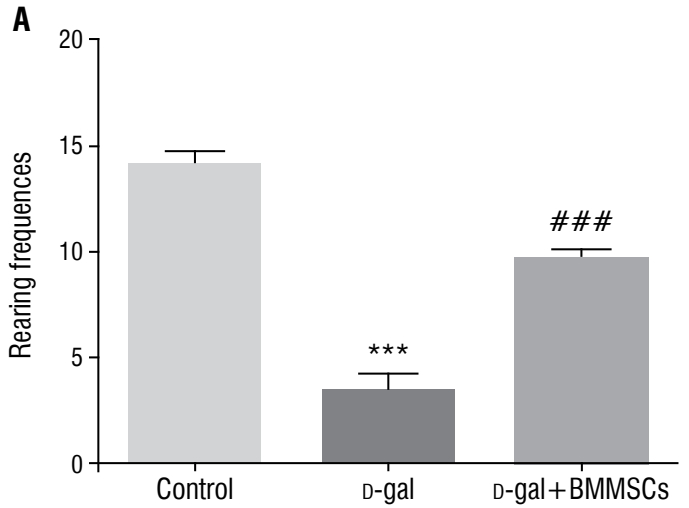

C

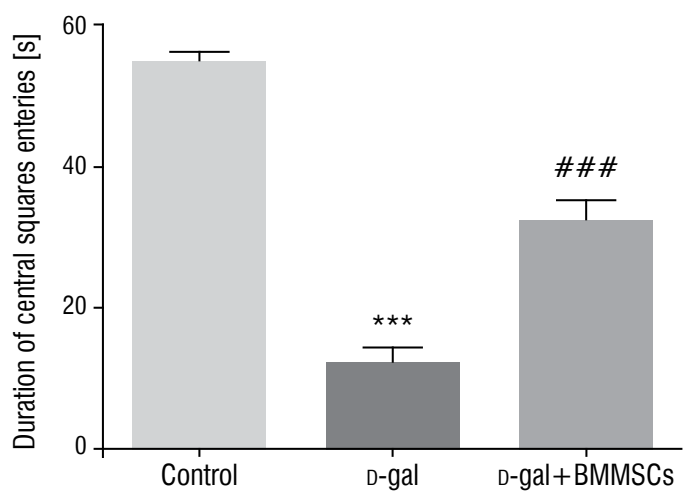

B

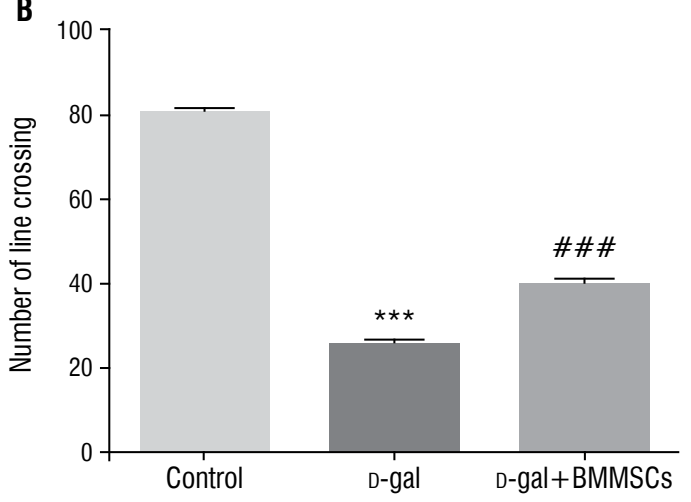

D

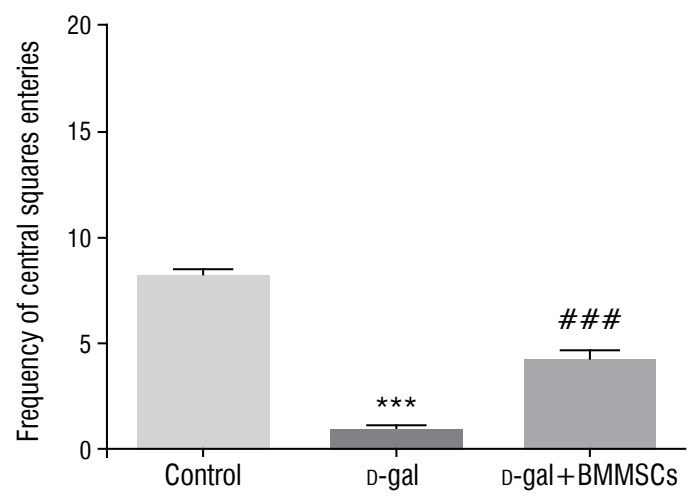

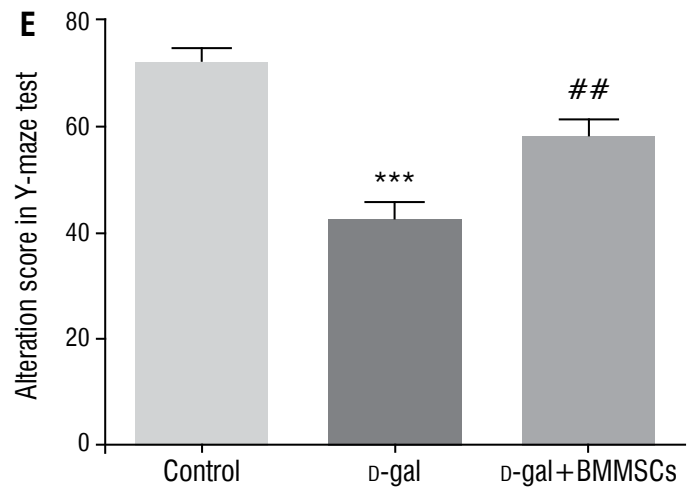

Figure 3. A-E. Locomotion, exploratory behaviour, spatial working memory, and anxiety were evaluated in control, aged (D-gal), and transplanted (D-gal + BMMSCs) rats. Locomotion and explanatory behaviour (horizontal locomotion and vertical rearing) and anxious behaviour (frequency and duration of central squares entries) were assessed for $5 \mathrm{~min}$ in an open field test, and spontaneous alternations between the arms of a Y-maze was assessed for $8 \mathrm{~min} ;{ }^{* * * P}<0.001$ vs. control rats; ${ }^{\# \# P}<0.01$ and ${ }^{\# \# \# ~}<0.001$ vs. aged rats. Data are expressed as means \pm standard error of mean; $N=10 /$ group; BMMSCs — bone marrow-derived mesenchymal stem cells.

as indicated by an increased alternation score when compared to that of the aged group (Fig. 3E).

\section{BMMSCs restore cholinergic system function}

The functional integrity of the cholinergic system in the cerebral cortex and hippocampus is largely affected during aging $[18,20,46]$. The correlation between cholinergic system hypofunction and cog- nitive deficits has led to the formulation of the cholinergic hypothesis of cognitive impairments in aging and $A D$ [46]. Gene expression of the main functional elements of cholinergic neurons was assessed in the different groups. Gene expression of ChAT for acetylcholine synthesis; high-affinity choline transporter 1 (ChT1) and the vesicular ACh transporter (VAChT) for $\mathrm{ACh}$ transport into the vesicles; and the cholinergic 

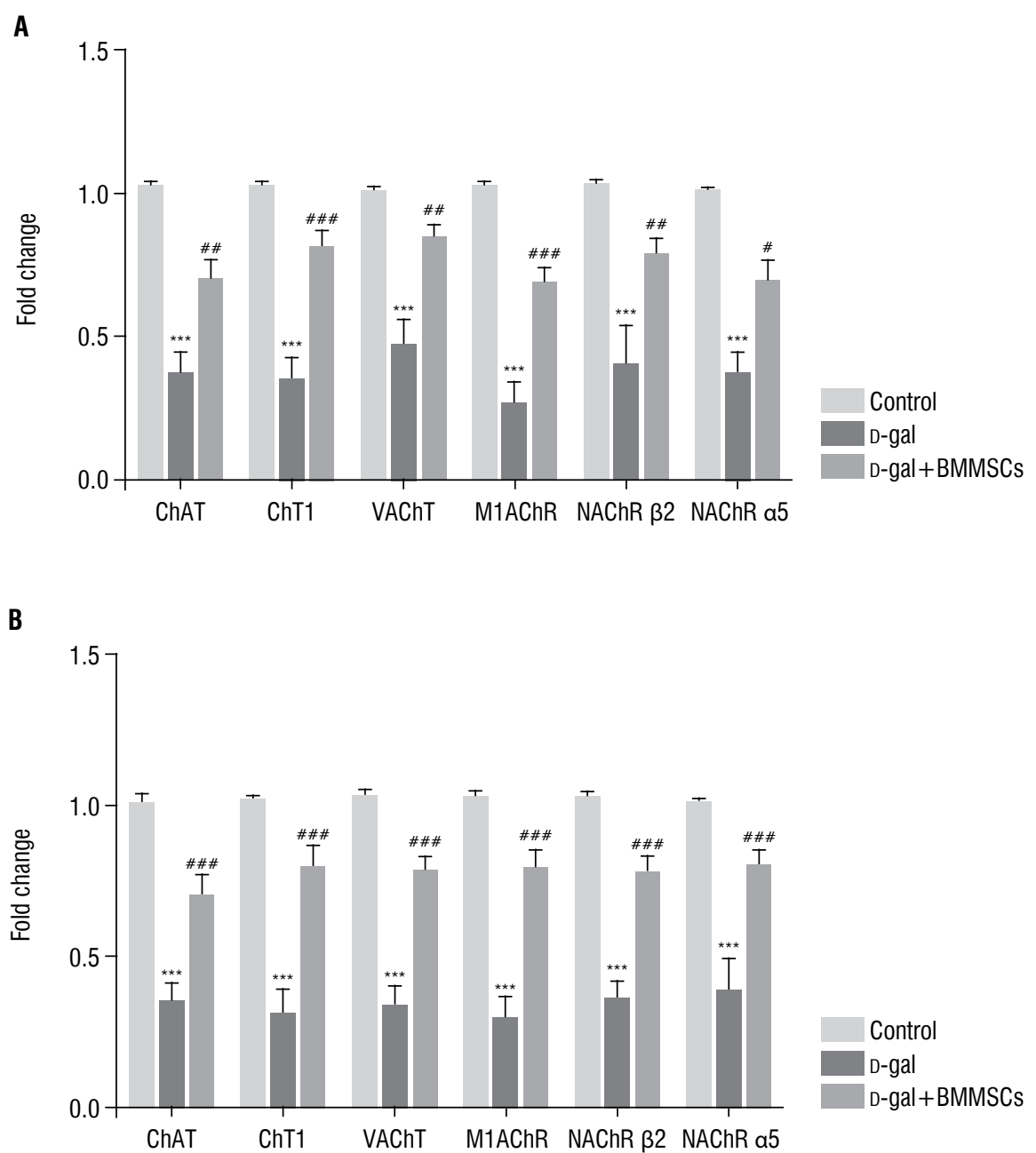

Figure 4. Gene expression of cholinergic nervous system markers in the cortex (A) and hippocampus (B) in control, aged (D-gal), and transplanted (D-gal + BMMSCs) rats as measured by quantitative reverse-transcription polymerase chain reaction; ${ }^{* * *} \mathrm{P}<0.001 \mathrm{vs.} \mathrm{control} \mathrm{rats;}$

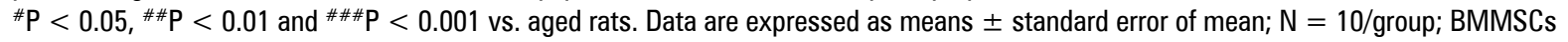
- bone marrow-derived mesenchymal stem cells.

muscarinic (m1AChR) and nicotinic ACh receptors (nAChR $\alpha 5$ and $n A C h R ~ \beta 2)$ for synaptic signalling were decreased in both the cortex (Fig. 4A) and the hippocampus (Fig. 4B) of aged as compared with control rats. These changes in gene cholinergic nerve marker expression were markedly prevented in the D-gal + BMMSCs group in both the cortex and the hippocampus (Fig. 4A, B).

\section{Transplanted BMMSCs survive and migrate to the brain, and differentiate into neurons and astrocytes}

To assess the potential mechanisms by which BMMSCs improved motor and cognitive deficits and restored cholinergic system alterations, we first assessed whether the systemically administered BMMSCs homed to and survived in the brains of the transplanted rats. PKH-labelled transplanted BMMSCs were found in brain sections of the transplanted group and were detected extensively in all examined brain regions. To characterise the fate of the migrated cells, the cells were recognised by PKH labelling, while their differentiation status was confirmed based on the expression of the neuronal marker Neun or the astrocyte marker glial fibrillary acidic protein (GFAP). In the cerebral cortices and hippocampi of transplanted rats, approximately $10 \%$ and $30 \%$ of the PKH-labelled cells co-expressed Neun (Fig. 5), and GFAP (Fig. 6), respectively, whereas a few transplanted cells expressed ChAT.

\section{BMMSC transplantation protects cholinergic neurons in the basal forebrain}

The cholinergic system involves neurons found mainly in the basal forebrain and their long axons 


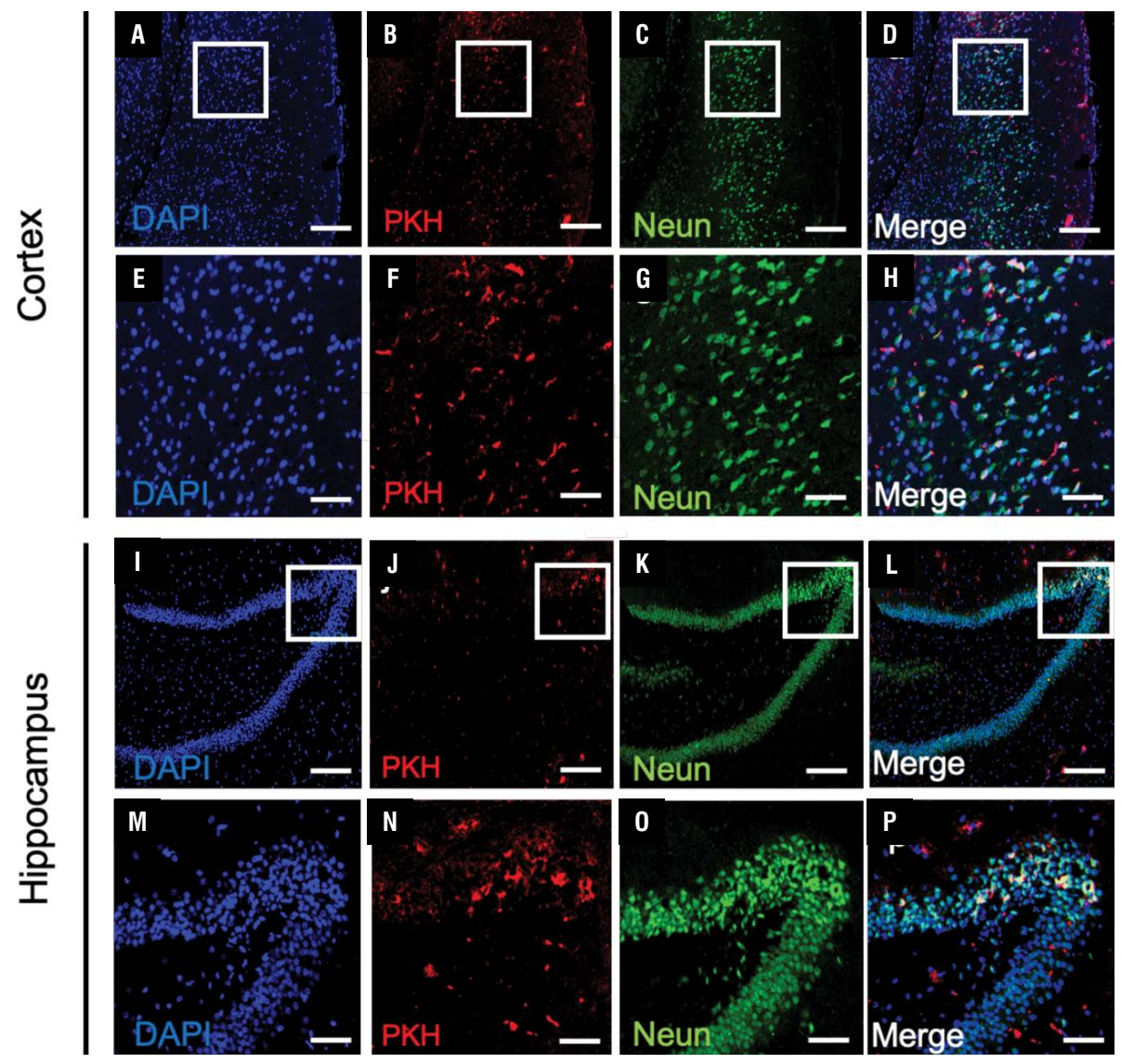

Figure 5. Survival and differentiation of transplanted bone marrow-derived mesenchymal stem cells (BMMSCs) into neurons in transplanted (D-gal + BMMSCs) rats. A number of PKH-labelled BMMSCs (red) $(\mathbf{B}, \mathbf{J})$ co-expressed Neun (green) in the cortex (C, D) and in the hippocampus (K, L). The boxed areas in $\mathbf{A}-\mathbf{D}$ and $\mathbf{I}-\mathbf{L}$ are magnified in $\mathbf{E}-\mathbf{H}$ and $\mathbf{M}-\mathbf{P}$, respectively. PKH-labelled cells (red) $(\mathbf{B}, \mathbf{F}, \mathbf{J}, \mathbf{N}$ ), Neun-positive cells (green) (C, G, K, O), DAPI-stained nuclei (blue) (A, E, I, M), and merged images (D, H, L, P). Scale bar $=500 \mu \mathrm{m}(\mathrm{A}-\mathrm{D}, \mathrm{I}-\mathrm{L})$ and $100 \mu \mathrm{m}(\mathrm{E}-\mathrm{H}, \mathrm{M}-\mathrm{P})$.

that projects diffusely to the cerebral cortex and the hippocampus. To determine whether BMMSC transplantation rescued atrophic cholinergic neurons in the basal forebrain in aged rats, ChAT-positive neurons were analysed. In D-gal-treated rats, ChAT-positive cells in the basal forebrain were markedly declined (Fig. 7A, B, D), whereas in the transplanted group, they were markedly increased (Fig. 7B-D). In the transplanted rats, some $\mathrm{PKH}$-labelled cells in the basal forebrain co-expressed ChAT (Fig. 7C'-C'"').

\section{BMMSCs exert antioxidative effects and restore neurotrophic factors}

One of the most well accepted theories for the mechanistic cause of brain ageing is the free-radical hypothesis of aging [26]. D-gal-treated rats had higher levels of MDA, an index of lipid peroxidation, in their cerebral cortex and hippocampus than control rats (Fig. 8A, C). In addition, the GSH levels in these brain regions were significantly (Fig. 8B, D) reduced in aged compared to control rats. In D-gal + BMMSCs-treated rats, MDA levels in the cerebral cortices and hippocampi were significantly reduced (Fig. 8A, C), whereas the GSH levels were increased (Fig. 8B, D) when compared with the levels in D-gal-treated rats.

Neurotrophic factors, such as BDNF, NGF, and vascular endothelial growth factor (VEGF) play important role in cholinergic innervation and ChAT activity in the cortex and hippocampus, and their decline has been linked to impaired cognitive function in aged animals $[23,79]$. The expression of $B D N F, N G F$, and $V E G F$ in the cortex and hippocampus were remarkably decreased in aged rats (Fig. 9) when compared with the expression in control rats, and these declines were suppressed in both brain regions (Fig. 9) after BMMSC transplantation.

BMMSCs modulate hippocampal synaptic plasticity by upregulating the PSD95 expression and triggering Egr1 expression

The PSD95 protein is a component of the postsynaptic complex and plays a crucial role in synaptic plas- 

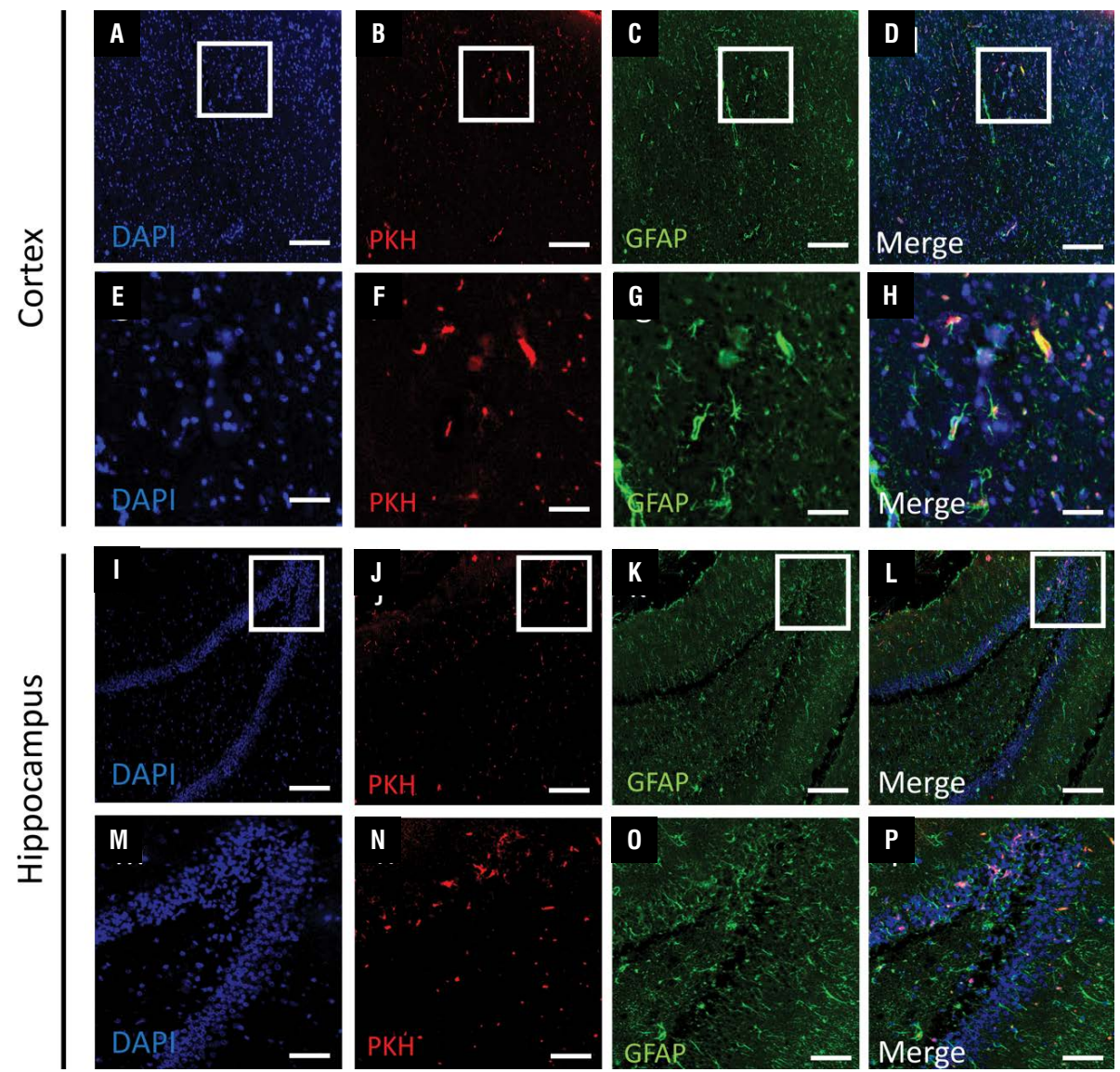

Figure 6. Survival and differentiation of transplanted bone marrow-derived mesenchymal stem cells (BMMSCs) into astrocytes in the transplanted (D-gal + BMMSCs) group. A number of PKH-labelled BMMSCs (red) (B, J) co-expressed GFAP (green) in the cortex (C, D) and in the hippocampus (K, L). The boxed areas in A-D and $\mathbf{I}-\mathbf{L}$ are magnified in $\mathbf{E}-\mathbf{H}$ and $\mathbf{M}-\mathbf{P}$, respectively. PKH-labelled cells (red) (B, F, J, N), GFAP-positive cells (green) $(\mathbf{C}, \mathbf{G}, \mathbf{K}, \mathbf{0})$, DAPI-stained nuclei (blue) (A, E, I, M) and merged images (D, H, L, P). Scale bar $=500 \mu \mathrm{m}(\mathrm{A}-\mathrm{D}, \mathrm{I}-\mathrm{L})$ and $100 \mu \mathrm{m}(\mathrm{E}-\mathrm{H}, \mathrm{M}-\mathrm{P})$.

ticity [16]. The numbers of PSD95-positive neurons in the hippocampus were markedly decreased in aged rats (Fig. 10A, B), whereas they were significantly increased in the transplanted group (Fig. 10A, B).

Reduced transcription of early growth response protein 1 (Egr1), an immediate early gene, in the hippocampus has been related to age-related memory deficits [21, 62, 93]. Egr1 expression in the hippocampus was reduced in aged rats when compared with control rats (Fig. 10C), but was significantly restored in BMMSCs + D-gal rats (Fig. 10C).

\section{DISCUSSION}

In the central nervous system, aging is associated with altered structure and connectivity, which leads to a decline in normal function. The decreases in neuron numbers and brain function during aging may be a determinant factor in the morphological and functional changes observed in neurodegenerative diseases $[19,34,63,71,94]$. These changes are accompanied by the deterioration of motor coordination and cognition in normal aging, which is worsened in age-associated neurodegenerative disorders such as $\operatorname{AD}[8,11,35,52,53]$. Thus, therapeutic strategies to ameliorate primary (normal) aging are a major goal in aging research $[3,42,43$, $64,75,94]$. The replenishment of lost/malfunctioning cells by stem cell therapy has become the focus of recent research. Studies have demonstrated the therapeutic potential of different types of MSCs such as adipose-, umbilical cord (UC)-, and amniotic-derived MSCs in rodent aging models $[17,39,61$, $74,91]$. Given the lack of proof for the superiority of specific source of MSCs in alleviating structural and functional alterations in different parts of the aging brain as well as for the most effective injection route [84], this study aimed to evaluate, for the first time, the potential beneficial outcome of intravenous transplantation of BMMSCs on the brain in D-gal aging rats. 

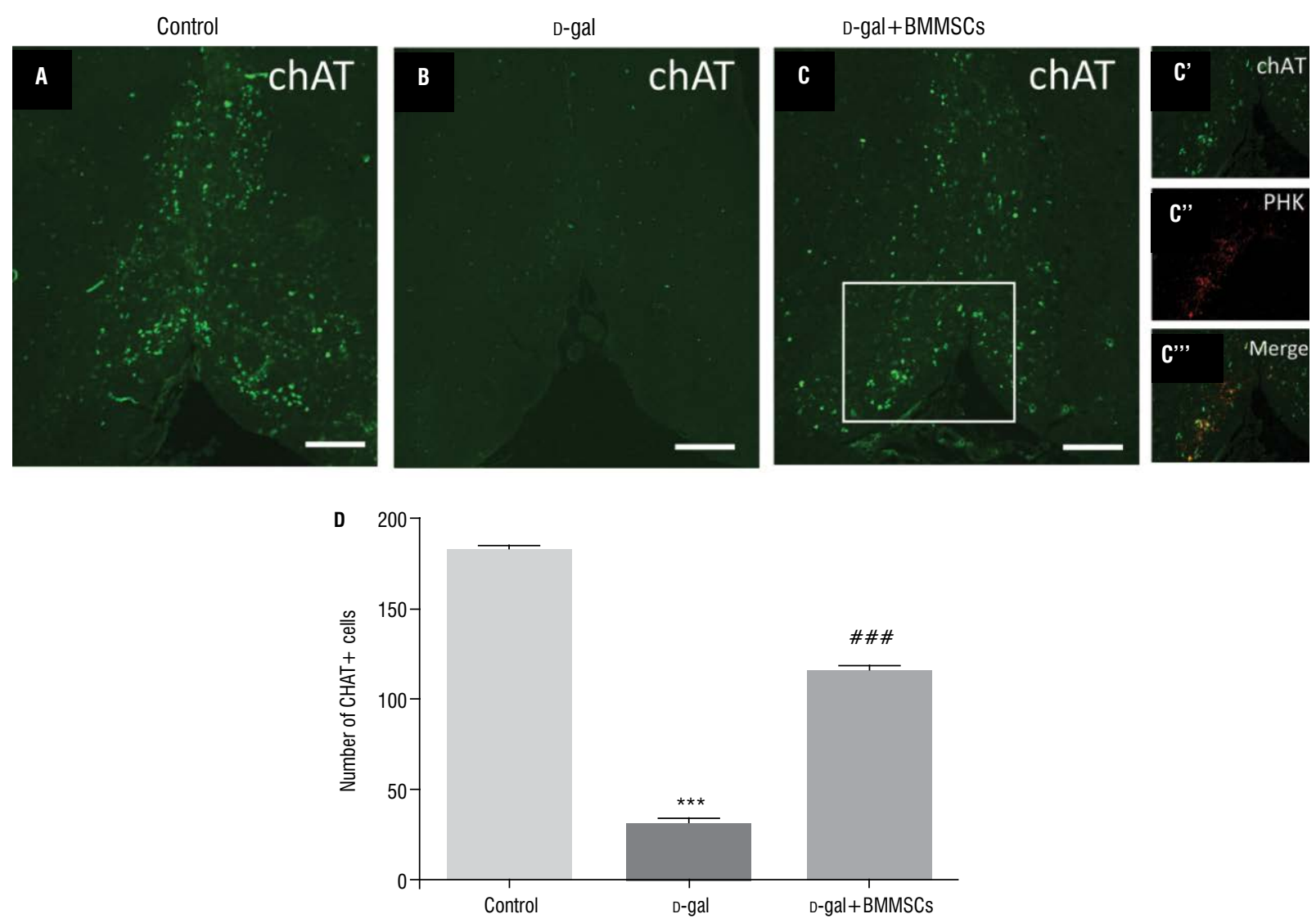

Figure 7. Number of cholinergic neurons in the basal forebrain in control, aged (D-gal), and transplanted (D-gal + BMMSCs) rats. A number of PKH-labelled BMMSCs (C'", red) co-expressed ChAT (C'"', green). The boxed areas in panel C are magnified in panel $\mathbf{C}^{\prime}$. PKH-labelled cells (red) $\left(\mathbf{C}^{\prime \prime}\right)$, ChAT-positive cells (green) $\left(\mathbf{A}-\mathbf{C}\right.$ and $\left.\mathbf{C}^{\prime}\right)$, and merged images ( $\left.\mathbf{C}^{\prime \prime \prime}\right)$. Scale bar $=500 \mu \mathrm{m} \mathrm{A}-C_{;}{ }^{* * * P}<0.001$ vs. control rats;

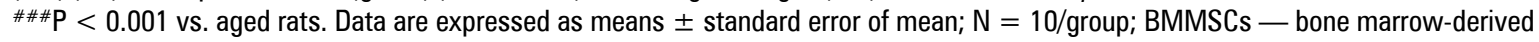
mesenchymal stem cells.

Aging is featured by a gradual decline in locomotion and cognition. With aging, various aspects of learning and memory progressively decline. In our study, BMMSCs improved exploratory behaviour, locomotion, and anxiety in D-gal + BMMSCs rats. Our results are consistent with previous findings. Intra-cerebroventricular human BMMSC transplantation in aged rats improved spatial memory accuracy capacity in locating goal sector in a Barnes maze [91]. Spatial learning and memory functions in D-gal aging mice enhanced after repeated intraperitoneal injections of hUCMSCs [17]. Repeated intravenous transplantations of human amniotic membrane (AM)-derived MSCs (AMMSCs) or adipose tissue (AD)-derived MSCs (ADMSCs) in 10-month-old male F344 rats improved motor coordination and cognitive function as indicated by improved rotarod, passive avoidance, and Morris water-maze performance [39]. Similarly, single or repeated intravenous or intra-cerebroventricular transplantation of ADMSCs increased physical activity and enhanced learning and memory performance in aged mice [61].

The strong involvement of the cholinergic circuits in age-related brain functional deterioration has led to the development of cholinergic hypothesis of geriatric cognitive impairments $[9,30,72,77,81]$. In normal aged brains, loss of cholinergic neurons, depletion of ACh, reduced ChAT activity, and declines in the densities of muscarinic and nicotinic ACh receptors have been reported $[9,18,28,49,72,77$, 82]. Based on positron emission tomography, Albin et al. [2] reported region-specific declines in VAChT binding sites in the cortex and striatum in the aged brain. In our study, the gene expression of the cholinergic factors ChAT, ChT1, VAChT, m1AChR, and nAChRs $\alpha 5$ and $\beta 2$ was increased in transplanted compared to aged rats. Therefore, it is plausible to conclude that the detected improvements in cognitive and motor activities might be due to improvements in the cholinergic system. 
A

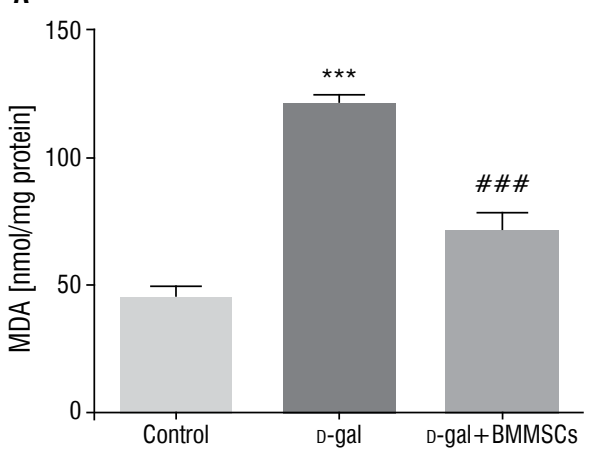

C

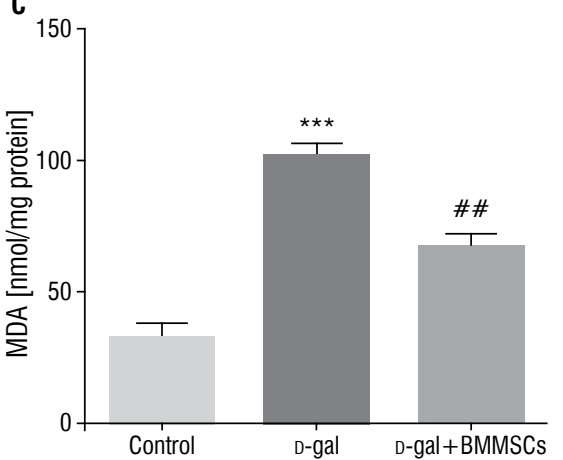

B
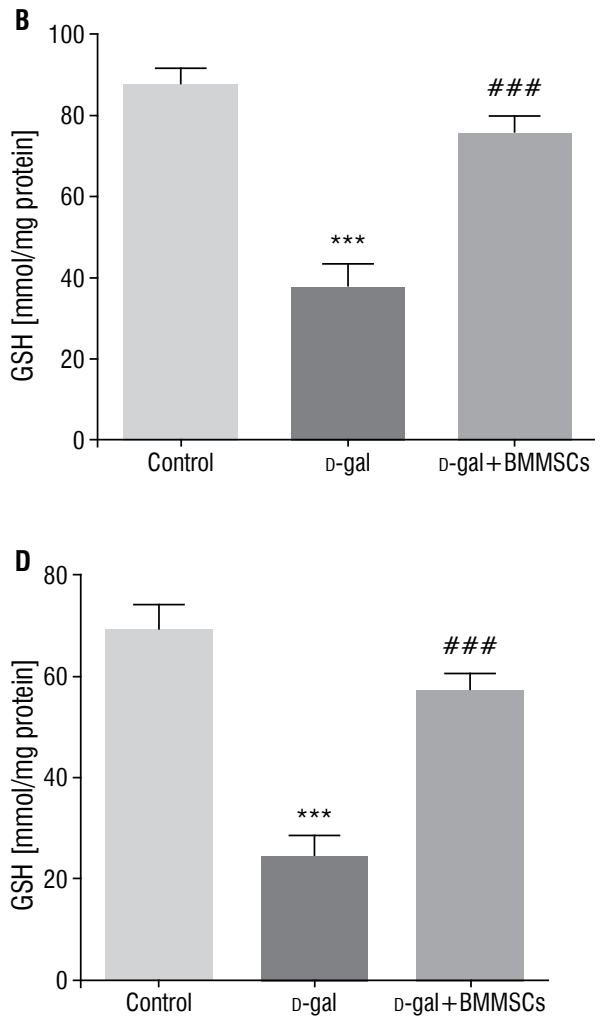

Figure 8. A-D. Status of malondialdehyde (MDA) and glutathione (GSH) in the cortex (A, B) and the hippocampus (C, D) of control, aged

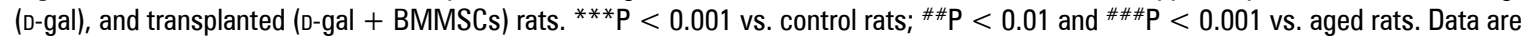
expressed as means \pm standard error of mean; $N=10$ /group; BMMSCs - bone marrow-derived mesenchymal stem cells.
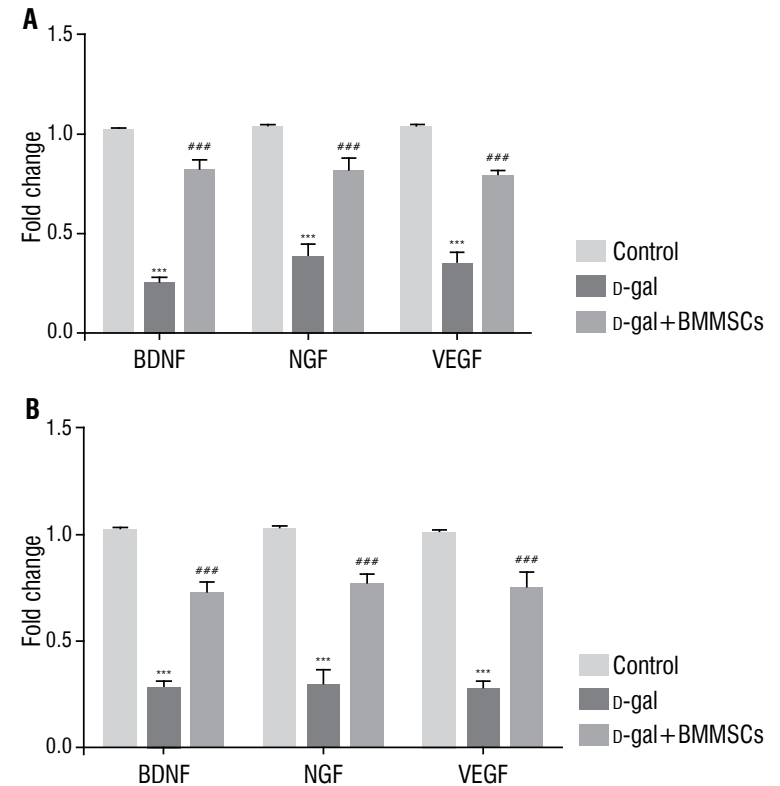

Figure 9. Gene expression of BDNF, NGF, and VEGF in the cortex (A) and the hippocampus (B) of control, aged (D-gal), and transplanted (D-gal + BMMSCs) rats as measured by quantitative reverse-transcription polymerase chain reaction. ${ }^{* *} \mathrm{P}<0.001$ vs. control

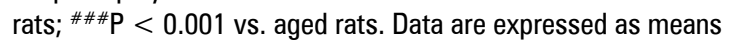
\pm standard error of mean; $N=10$ group; BMMSCs - bone marrow-derived mesenchymal stem cells.
To reveal the mechanism underlying the behavioural and cholinergic functional improvements observed after BMMSC injection, we evaluated the survival, migration, and differentiation potential of the transplanted BMMSCs in D-gal aging rats. Repeated intravenous BMMSC transplantation was accompanied with a massive migration of the cells into all brain regions examined. These results were in line with previous findings. Interestingly, in both animals and humans, aging has been linked with increased blood-brain barrier permeability, which might be triggered by several aging-mediated events, such as increased oxidative stress and enhanced microglial activation $[66,76]$. Demonstrating the therapeutic efficacy of a relatively non-invasive approach such as the intravenous route is of clinical relevance as invasive implantation techniques such as intracranial transplantation may damage intact brain tissues, increasing the burden of aging-related cell loss. Approximately $10 \%$ of the migrated cells differentiated into neurons and $30 \%$ differentiated into astrocytes. In addition, only few transplanted cells differentiated into ChAT+ cells. Substantial evidence suggests 
A

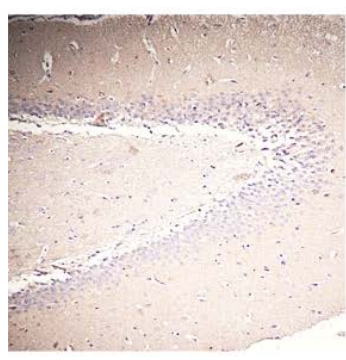

B

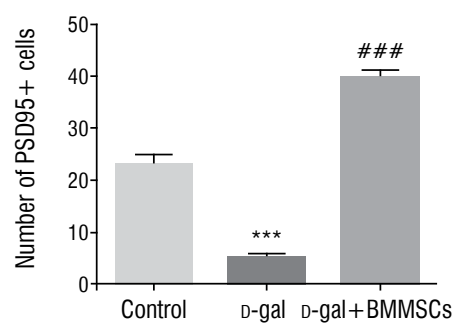

D-gal

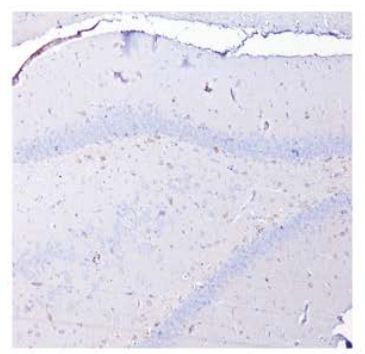

C

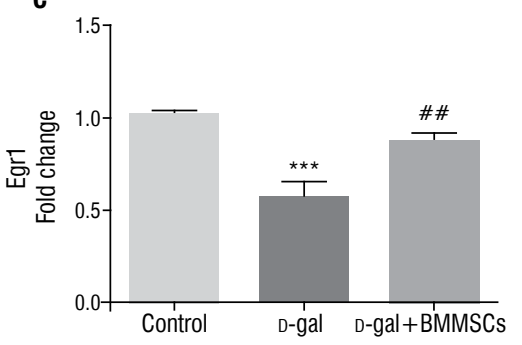

D-gal+BMMSCs

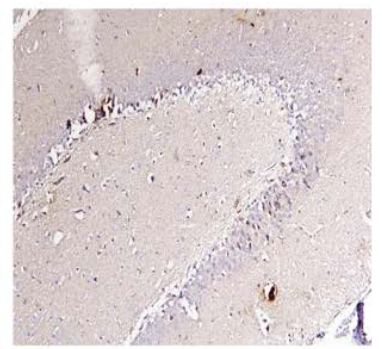

\section{(1)}

Figure 10. PSD95 expression as indicated by immunohistochemical staining (A, B) and Egr1 gene expression as indicated by quantitative reverse-transcription polymerase chain reaction (C) in the hippocampus of control, aged (D-gal), and transplanted (D-gal + BMMSCs) rats. ${ }^{* * *} P<0.001$ vs. control rats; ${ }^{\# \# P}<0.001$ and ${ }^{\# \# \# P}<0.001$ vs. aged rats. Data are expressed as means \pm standard error of mean; $\mathrm{N}=10$ /group; BMMSCs — bone marrow-derived mesenchymal stem cells.

that BMMSCs can differentiate into neurons, and in particular, ChAT neurons $[1,5,6,12,32,55,67,78$, $80,88,89]$. The capabilities of intravenously injected MSCs from different sources to migrate and differentiate into the neuronal fate have been previously reported. In 10-month-old male F344 rats, repeated intravenously transplanted hAMMSC and hADMSCs homed to the cerebral cortex and hippocampus and differentiated into neurons, some of which co-expressed ChAT, and, in part, into astrocytes [39]. Similar results have been reported after repeated intravenous transplantation of hADMSCs [61]. However, these studies reported a higher potential of the transplanted cells to differentiate into neuronal phenotypes; in particular, ChAT-positive cells, than we observed. Differences in aging animal models, tissue source and species of the MSCs, and intravenous dose frequency may account for this discrepancy.

Previous studies have shown that the differentiation of transplanted cells into neurons and their subsequent projection to the target anatomical region is challenging, and that the beneficial effects observed in the transplanted brains could be mainly explained by transplanted stem cell-mediated protection rather than replacement. The cholinergic system involves neurons found mainly in the basal forebrain and their long axons that projects diffusely to the cerebral cortex and the hippocampus. We observed limited differentiation of the transplanted cells into the neuronal fate in the cortex and hippocampus. Interestingly, we observed a significant increase in the number of endogenous ChAT-positive cells in the basal forebrain in transplanted rats when compared with aged rats, which cannot be explained by the limited number of transplanted cells that colocalised with ChAT immunostaining in the basal forebrains of these rats. These results indicated an endogenous regeneration of the host cholinergic system in the basal forebrain in transplanted rats. Therefore, we next sought to assess potential bystander-like mechanisms mediated by the transplanted BMMSCs that would contribute to the endogenous regeneration of the host cholinergic system and lead to the observed beneficial effects on functional and cognitive activities.

Cholinergic neurons in the basal forebrain depend for their survival and function on neurotrophic factors, such as BDNF and NGF, which are retrogradely transported from basal forebrain targets. Aging is accompanied by alterations in the neurotrophic signalling pathways, which have crucial roles in the cholinergic and cognitive deficits found in aging and $A D[14,15,23,50,51,79]$. In cultured embryonic rat basal forebrain and cortical neurons in microfluidic chambers used as models of normal aging, significant declines in BDNF and proNGF transport have been observed, suggesting the susceptibility of aged forebrain cholinergic neurons to age-induced transport 
malfunction [73]. BDNF-knockout mice possessed reduced numbers of cholinergic cells in the medial septum, which was associated with reduced ChAT activity and NGF expression in the hippocampus [27]. We observed decreased BDNF and NGF expressions in both the hippocampus and cortex in D-gal aging rats, which is in line with findings reported in several previous studies [24, 37, 44, 57]. These decreases were remarkably restored in BMMSC-transplanted rats. A substantial body of evidence suggests the neurotrophic and paracrine potential of stem cell transplantation, which is accomplished by increased concentrations of various neurotrophic factors such as BDNF, NGF, and glial cell-derived neurotrophic factor [7]. BDNF and NGF levels in F344 rat brains markedly increased after transplantation of hAMMSC and hADMSCs [56], and in aged mice after transplantation of ADMSCs [61]. In addition, hBMMSCs upregulate the BDNF level, rescuing cultured rodent cortical neurons from degeneration by trophic factor absence or oxidative stress [86] and ameliorating spinal cord injury in vivo by increasing both BDNF and NGF levels [69]. Hence, the observed restoration of cholinergic functions is most likely due to the secretion of neurotrophic factors by the migrated cells, which were then taken up by projected axonal terminals and retrogradely transported into cholinergic neuron bodies, preventing their loss.

To explore the pathways involved in the observed improvement of cognitive deficits in BMMSCs + D-galrats, we investigated factors involved in synaptic activity and plasticity. Reduced transcription of the immediate early gene Egr1 in the hippocampus has been related to age-related memory deficits $[21,62$, 93]. Our results showed that Egr1 expression was reduced in the hippocampi of aged rats when compared with control rats. The restoration of competent spatial memory in the water maze test correlated with Egr1 expression in the hippocampi of aged mice [93]. In the present study, BMMSC transplantation triggered Egr1 expression in the hippocampus in aging rats. Cao et al. [17] reported that hUCMSCs stimulated the intracellular MAPK-ERK signalling and subsequently enhanced several effectors, including Egr1 and PSD95. These effectors play important roles in neuron morphology, synaptic plasticity, and cognitive integrity in aged brain. Therefore, it is likely that the enhancement of Egr1 expression by BMMSCs in transplanted rats have contributed to the countering of the age-related cognitive decline.

\section{Limitations of the study}

Our study had some limitations. First, neuronal differentiation of the transplanted cells was limited. Enhancing the neuronal differentiation of the transplanted cells would further improve their therapeutic capacity; therefore, optimising strategies to further improve the neuronal differentiation potential of the transplanted cells are needed. Second, the effect of transplanted cells on neurogenesis was not assessed. Third, the transplanted BM population did not represent pure MSCs. According to phenotypic profiling, 9.5\% of the BMMSCs utilised in this study expressed CD34. This cell population may have contributed to the beneficial effects observed in this study. Finally, the optimisation of the cell-delivery protocol, including the number of transplanted cells, frequency of injections, and route of delivery requires further investigation.

\section{CONCLUSIONS}

The current study demonstrated that intravenous transplantation of BMMSCs prevented cognitive and physical deficits in a D-gal aging rat model by restoring cholinergic system function, protecting atrophic cholinergic neurons in the basal forebrain, inducing antioxidative effects and restoring neurotrophic factors, and modulating hippocampal synaptic plasticity by triggering PSD95 and Egr1 expression. Our results provide evidence of the usability of systemic transplantation of BMMSCs as a potential therapeutic approach for the prevention of neurodegenerative changes associated with aging. However, prior to commencing clinical trials, further studies are needed to enhance the differentiation of these cells into the neuronal fate in vivo and to untangle the molecular mechanisms underlying the beneficial effects of BMMSC-secreted factors.

\section{Acknowledgments}

We would like to thank Cell Biology Department, King Faisal Specialist Hospital for giving access to the imaging fluorescence microscope laboratory.

\section{Funding}

This research project was funded by Health Sciences Research Centre, King Abdullah bin Abdulaziz University Hospital, Princess Nourah bint Abdulrahman University, through the Research Funding Programme, grant no. G18-00015.

Conflict of interest: None declared 


\section{REFERENCES}

1. Abdullah RH, Yaseen NY, Salih SM, et al. Induction of mice adult bone marrow mesenchymal stem cells into functional motor neuron-like cells. J Chem Neuroanat. 2016; 77: 129-142, doi: 10.1016/j.jchemneu.2016.07.003, indexed in Pubmed: 27417692.

2. Albin RL, Bohnen NI, Muller ML, et al. Regional vesicular acetylcholine transporter distribution in human brain: A [18 F]fluoroethoxybenzovesamicol positron emission tomography study. J Comp Neurol. 2018; 526(17): 2884-2897, doi: 10.1002/cne.24541, indexed in Pubmed: 30255936.

3. Artegiani B, Calegari F. Age-related cognitive decline: can neural stem cells help us? Aging (Albany NY). 2012; 4(3): 176-186, doi: 10.18632/aging.100446, indexed in Pubmed: 22466406.

4. Badyra B, Sułkowski M, Milczarek O, et al. Mesenchymal stem cells as a multimodal treatment for nervous system diseases. Stem Cells Transl Med. 2020; 9(10): 1174-1189, doi: 10.1002/sctm.19-0430, indexed in Pubmed: 32573961.

5. Bae KS, Park JB, Kim HS, et al. Neuron-like differentiation of bone marrow-derived mesenchymal stem cells. Yonsei Med J. 2011; 52(3): 401-412, doi: 10.3349/ymj.2011.52.3.401, indexed in Pubmed: 21488182.

6. Bai $W F$, Zhang $Y, X u$ W, et al. Isolation and characterization of neural progenitor cells from bone marrow in cell replacement therapy of brain injury. Front Cell Neurosci. 2020; 14: 49, doi: 10.3389/fncel.2020.00049, indexed in Pubmed: 32226361.

7. Bali P, Lahiri DK, Banik A, et al. Potential for stem cells therapy in Alzheimer's disease: do neurotrophic factors play critical role? Curr Alzheimer Res. 2017; 14(2): 208-220, doi: $10.2174 / 1567205013666160314145347$, indexed in Pubmed: 26971940.

8. Barrientos RM, Kitt MM, Watkins LR, et al. Neuroinflammation in the normal aging hippocampus. Neuroscience. 2015; 309: 84-99, doi: 10.1016/j.neuroscience.2015.03.007, indexed in Pubmed: 25772789.

9. Bekdash RA. The cholinergic system, the adrenergic system and the neuropathology of Azheimer's disease. Int J Mol Sci. 2021; 22(3), doi: 10.3390/ijms22031273, indexed in Pubmed: 33525357.

10. Berebichez-Fridman R, Montero-Olvera PR. Sources and clinical applications of mesenchymal stem cells: state-ofthe-art review. Sultan Qaboos Univ Med J. 2018; 18(3): e264-e277, doi: 10.18295/squmj.2018.18.03.002, indexed in Pubmed: 30607265.

11. Bishop NA, Lu T, Yankner BA. Neural mechanisms of ageing and cognitive decline. Nature. 2010; 464(7288): 529-535, doi: 10.1038/nature08983, indexed in Pubmed: 20336135.

12. Borkowska P, Fila-Danilow A, Paul-Samojedny $M$, et al. Differentiation of adult rat mesenchymal stem cells to GABAergic, dopaminergic and cholinergic neurons. Pharmacol Rep. 2015; 67(2): 179-186, doi: 10.1016/j. pharep.2014.08.022, indexed in Pubmed: 25712637.

13. Bortolotti F, Ukovich $L$, Razban V, et al. In vivo therapeutic potential of mesenchymal stromal cells depends on the source and the isolation procedure. Stem Cell Reports. 2015; 4(3): 332-339, doi: 10.1016/j.stemcr.2015.01.001, indexed in Pubmed: 25660405.
14. Boskovic Z, Meier S, Wang Y, et al. Regulation of cholinergic basal forebrain development, connectivity, and function by neurotrophin receptors. Neuronal Signal. 2019; 3(1): NS20180066, doi: 10.1042/NS20180066, indexed in Pubmed: 32269831.

15. Budni J, Bellettini-Santos T, Mina $F$, et al. The involvement of BDNF, NGF and GDNF in aging and Alzheimer's disease. Aging Dis. 2015; 6(5): 331-341, doi: 10.14336/ AD.2015.0825, indexed in Pubmed: 26425388.

16. Bustos FJ, Ampuero E, Jury N, et al. Epigenetic editing of the DIg4/PSD95 gene improves cognition in aged and Alzheimer's disease mice. Brain. 2017; 140(12): 3252-3268, doi: 10.1093/brain/awx272, indexed in Pubmed: 29155979.

17. Cao N, Liao T, Liu J, et al. Clinical-grade human umbilical cord-derived mesenchymal stem cells reverse cognitive aging via improving synaptic plasticity and endogenous neurogenesis. Cell Death Dis. 2017; 8(8): e2996, doi: 10.1038/cddis.2017.316, indexed in Pubmed: 28796260.

18. Casu MA, Wong TP, De Koninck Y, et al. Aging causes a preferential loss of cholinergic innervation of characterized neocortical pyramidal neurons. Cereb Cortex. 2002; 12(3): 329-337, doi: 10.1093/cercor/12.3.329, indexed in Pubmed: 11839606.

19. Daniele S, Giacomelli C, Martini C. Brain ageing and neurodegenerative disease: The role of cellular waste management. Biochem Pharmacol. 2018; 158: 207-216, doi: 10.1016/j.bcp.2018.10.030, indexed in Pubmed: 30393045.

20. Daulatzai MA. Early stages of pathogenesis in memory impairment during normal senescence and Alzheimer's disease. J Alzheimers Dis. 2010; 20(2): 355-367, doi: 10.3233/JAD-2010-1374, indexed in Pubmed: 20164576.

21. Duclot F, Kabbaj $M$. The role of early growth response 1 (EGR1) in brain plasticity and neuropsychiatric disorders. Front Behav Neurosci. 2017; 11: 35, doi: 10.3389/fnbeh.2017.00035, indexed in Pubmed: 28321184.

22. Ellman G. Tissue sulfhydryl groups. Arch Biochem Biophys. 1959; 82(1): 70-77, doi: 10.1016/0003-9861(59)90090-6.

23. Erickson KI, Prakash RS, Voss MW, et al. Brain-derived neurotrophic factor is associated with age-related decline in hippocampal volume. J Neurosci. 2010; 30(15): 5368-5375, doi: 10.1523/JNEUROSCI.6251-09.2010, indexed in Pubmed: 20392958.

24. Fatemi I, Khaluoi A, Kaeidi A, et al. Protective effect of metformin on D-galactose-induced aging model in mice. Iran J Basic Med Sci. 2018; 21(1): 19-25, doi: 10.22038/JJBMS.2017.24331.6071, indexed in Pubmed: 29372032.

25. Ge M, Zhang Y, Hao Q, et al. Effects of mesenchymal stem cells transplantation on cognitive deficits in animal models of Alzheimer's disease: a systematic review and meta-analysis. Brain Behav. 2018; 8(7): e00982, doi: 10.1002/brb3.982, indexed in Pubmed: 29877067.

26. Gemma C, Vila J, Bachstetter A, Bickford PC. Oxidative stress and the aging brain: from theory to prevention. In: riddle DR (ed.). Brain aging: models, methods, and mechanisms. Frontiers in neuroscience. Boca Raton, FL 2007.

27. Grosse G, Djalali S, Deng DR, et al. Area-specific effects of brain-derived neurotrophic factor (BDNF) genetic ablation on various neuronal subtypes of the mouse brain. Brain 
Res Dev Brain Res. 2005; 156(2): 111-126, doi: 10.1016/j. devbrainres.2004.12.012, indexed in Pubmed: 16099299.

28. Grothe M, Heinsen H, Teipel SJ. Atrophy of the cholinergic Basal forebrain over the adult age range and in early stages of Alzheimer's disease. Biol Psychiatry. 2012; 71(9): 805-813, doi: 10.1016/j.biopsych.2011.06.019, indexed in Pubmed: 21816388.

29. Hajjar I, Hayek SS, Goldstein FC, et al. Oxidative stress predicts cognitive decline with aging in healthy adults: an observational study. J Neuroinflammation. 2018; 15(1): 17, doi: 10.1186/s12974-017-1026-z, indexed in Pubmed: 29338747.

30. Hampel H, Mesulam MM, Cuello AC, et al. The cholinergic system in the pathophysiology and treatment of Alzheimer's disease. Brain. 2018; 141(7): 1917-1933, doi: 10.1093/brain/awy132, indexed in Pubmed: 29850777.

31. Harada CN, Natelson Love MC, Triebel KL. Normal cognitive aging. Clin Geriatr Med. 2013; 29(4): 737-752, doi: 10.1016/j.cger.2013.07.002, indexed in Pubmed: 24094294.

32. Hernandez CM, Gearhart DA, Parikh V, et al. Comparison of galantamine and donepezil for effects on nerve growth factor, cholinergic markers, and memory performance in aged rats. J Pharmacol Exp Ther. 2006; 316(2): 679-694, doi: 10.1124/jpet.105.093047, indexed in Pubmed: 16214877.

33. Hernández R, Jiménez-Luna $C$, Perales-Adán J, et al. Differentiation of human mesenchymal stem cells towards neuronal lineage: clinical trials in nervous system disorders. Biomol Ther (Seoul). 2020; 28(1): 34-44, doi: 10.4062/ biomolther.2019.065, indexed in Pubmed: 31649208.

34. Hou Y, Dan X, Babbar M, et al. Ageing as a risk factor for neurodegenerative disease. Nat Rev Neurol. 2019; 15(10): 565-581, doi: 10.1038/s41582-019-0244-7, indexed in Pubmed: 31501588.

35. Hu S, Li CSR. Age-Related structural and functional changes of the hippocampus and the relationship with inhibitory control. Brain Sci. 2020; 10(12), doi: 10.3390/ brainsci10121013, indexed in Pubmed: 33352718.

36. Hunsberger J, Rao M, Kurtzberg J, et al. Accelerating stem cell trials for Alzheimer's disease. Lancet Neurol. 2016; 15(2): 219-230, doi: 10.1016/s1474-4422(15)00332-4.

37. Ibrahim WW, Abdelkader NF, Ismail HM, et al. Escitalopram ameliorates cognitive impairment in D-galactose-injected ovariectomized rats: modulation of JNK, GSK-3beta, and ERK signalling pathways. Sci Rep. 2019; 9(1): 10056, doi: 10.1038/s41598-019-46558-1, indexed in Pubmed: 31296935

38. Isaev NK, Stelmashook EV, Genrikhs EE. Neurogenesis and brain aging. Rev Neurosci. 2019; 30(6): 573-580, doi: 10.1515/revneuro-2018-0084, indexed in Pubmed: 30763272

39. Kim D, Kyung J, Park D, et al. Health span-extending activity of human amniotic membrane- and adipose tissue-derived stem cells in F344 rats. Stem Cells Transl Med. 2015; 4(10): 1144-1154, doi: 10.5966/sctm.2015-0011, indexed in Pubmed: 26315571.

40. Kim Y, Kim H, Cho H, et al. Direct comparison of human mesenchymal stem cells derived from adipose tissues and bone marrow in mediating neovascularization in response to vascular ischemia. Cell Physiol Biochem. 2007; 20(6):
867-876, doi: 10.1159/000110447, indexed in Pubmed: 17982269.

41. Lee HJu, Lee JK, Lee $H$, et al. Human umbilical cord blood-derived mesenchymal stem cells improve neuropathology and cognitive impairment in an Alzheimer's disease mouse model through modulation of neuroinflammation. Neurobiol Aging. 2012; 33(3): 588-602, doi: 10.1016/j.neurobiolaging.2010.03.024, indexed in Pubmed: 20471717.

42. Li Z, Zhang Z, Ren Y, et al. Aging and age-related diseases: from mechanisms to therapeutic strategies. Biogerontology. 2021; 22(2): 165-187, doi: 10.1007/s10522-02109910-5, indexed in Pubmed: 33502634.

43. Limke TL, Rao MS. Neural stem cells in aging and disease. J Cell Mol Med. 2002; 6(4): 475-496, doi: 10.1111/j.15824934.2002.tb00451.x, indexed in Pubmed: 12611637.

44. Liu X, Wu C, Han D, et al. Partially hydrolyzed guar gum attenuates $\mathrm{D}$-galactose-induced oxidative stress and restores gut microbiota in rats. Int J Mol Sci. 2019; 20(19), doi: 10.3390/ijms20194861, indexed in Pubmed: 31574948.

45. Livak KJ, Schmittgen TD. Analysis of relative gene expression data using real-time quantitative PCR and the 2(-Delta Delta C(T)) Method. Methods. 2001; 25(4): 402-408, doi: 10.1006/meth.2001.1262, indexed in Pubmed: 11846609.

46. Lopez-Leon M, Reggiani PC, Claudia B, et al. Regenerative medicine for the aging brain. Enliven J Stem Cell Res Regen Med. 2014; 01(01), doi: 10.18650/2379-5751.11001.

47. Lushchak VI. Interplay between bioenergetics and oxidative stress at normal brain aging. Aging as a result of increasing disbalance in the system oxidative stress-energy provision. Pflugers Arch. 2021; 473(5): 713-722, doi: 10.1007/ s00424-021-02531-4, indexed in Pubmed: 33599804.

48. Ma S, Zang T, Liu ML, et al. Aging-relevant human basal forebrain cholinergic neurons as a cell model for Alzheimer's disease. Mol Neurodegener. 2020; 15(1): 61, doi: 10.1186/s13024-020-00411-6, indexed in Pubmed: 33087140.

49. Mesulam M. Cholinergic aspects of aging and Alzheimer's disease. Biol Psychiatry. 2012; 71(9): 760-761, doi: 10.1016/j.biopsych.2012.02.025, indexed in Pubmed: 22482884.

50. Miranda M, Morici JF, Zanoni MB, et al. Brain-derived neurotrophic factor: a key molecule for memory in the healthy and the pathological brain. Front Cell Neurosci. 2019; 13: 363, doi: 10.3389/fncel.2019.00363, indexed in Pubmed: 31440144.

51. Molinari C, Morsanuto V, Ruga S, et al. The role of BDNF on aging-modulation markers. Brain Sci. 2020; 10(5), doi: 10.3390/brainsci10050285, indexed in Pubmed: 32397504.

52. Morrison JH, Baxter MG. The ageing cortical synapse: hallmarks and implications for cognitive decline. Nat Rev Neurosci. 2012; 13(4): 240-250, doi: 10.1038/nrn3200, indexed in Pubmed: 22395804.

53. Mota C, Taipa R, das Neves SP, et al. Structural and molecular correlates of cognitive aging in the rat. Sci Rep. 2019; 9(1): 2005, doi: 10.1038/s41598-019-39645-w, indexed in Pubmed: 30765864.

54. Naaldijk Y, Jäger C, Fabian C, et al. Effect of systemic transplantation of bone marrow-derived mesenchymal stem cells on neuropathology markers in APP/PS1 Alzheimer 
mice. Neuropathol Appl Neurobiol. 2017; 43(4): 299-314, doi: 10.1111/nan.12319, indexed in Pubmed: 26918424.

55. Naghdi M, Tiraihi T, Namin SA, et al. Transdifferentiation of bone marrow stromal cells into cholinergic neuronal phenotype: a potential source for cell therapy in spinal cord injury. Cytotherapy. 2009; 11(2): 137-152, doi: 10.1080/14653240802716582, indexed in Pubmed: 19253075.

56. Nakano M, Kubota K, Kobayashi E, et al. Bone marrow-derived mesenchymal stem cells improve cognitive impairment in an Alzheimer's disease model by increasing the expression of microRNA-146a in hippocampus. Sci Rep. 2020; 10(1): 10772, doi: 10.1038/s41598-020-67460-1, indexed in Pubmed: 32612165.

57. Nam SM, Seo M, Seo JS, et al. Ascorbic acid mitigates D-galactose-induced brain aging by increasing hippocampal neurogenesis and improving memory function. Nutrients. 2019; 11(1), doi: 10.3390/nu11010176, indexed in Pubmed: 30650605.

58. Nasiri E, Alizadeh A, Roushandeh AM, et al. Melatonin-pretreated adipose-derived mesenchymal stem cells efficeintly improved learning, memory, and cognition in an animal model of Alzheimer's disease. Metab Brain Dis. 2019; 34(4): 1131-1143, doi: 10.1007/s11011-019-00421-4, indexed in Pubmed: 31129766.

59. Neves AF, Camargo C, Premer $C$, et al. Intravenous administration of mesenchymal stem cells reduces Tau phosphorylation and inflammation in the 3xTg-AD mouse model of Alzheimer's disease. Exp Neurol. 2021; 341: 113706, doi: 10.1016/j.expneurol.2021.113706, indexed in Pubmed: 33757765.

60. Oh SeH, Kim HaNa, Park HJ, et al. Mesenchymal stem cells increase hippocampal neurogenesis and neuronal differentiation by enhancing the wnt signaling pathway in an Alzheimer's disease model. Cell Transplant. 2015; 24(6): 1097-1109, doi: 10.3727/096368914X679237, indexed in Pubmed: 24612635.

61. Park D, Yang G, Bae DK, et al. Human adipose tissue-derived mesenchymal stem cells improve cognitive function and physical activity in ageing mice. J Neurosci Res. 2013; 91(5): 660-670, doi: 10.1002/jnr.23182, indexed in Pubmed: 23404260.

62. Penner MR, Parrish RR, Hoang LT, et al. Age-related changes in Egr1 transcription and DNA methylation within the hippocampus. Hippocampus. 2016; 26(8): 1008-1020, doi: 10.1002/hipo.22583, indexed in Pubmed: 26972614.

63. Peters R. Ageing and the brain. Postgrad Med J. 2006; 82(964): 84-88, doi: 10.1136/pgmj.2005.036665, indexed in Pubmed: 16461469.

64. Piccardi L, Curcio G, Palermo L, et al. Ageing and neurodegenerative disorders. Behav Neurol. 2015; 2015: 149532, doi: 10.1155/2015/149532, indexed in Pubmed: 26185358.

65. Polisetti N, Chaitanya VG, Babu PP, et al. Isolation, characterization and differentiation potential of rat bone marrow stromal cells. Neurol India. 2010; 58(2): 201-208, doi: 10.4103/0028-3886.63789, indexed in Pubmed: 20508336.

66. Popescu BO, Toescu EC, Popescu LM, et al. Blood-brain barrier alterations in ageing and dementia. J Neurol Sci.
2009; 283(1-2): 99-106, doi: 10.1016/j.jns.2009.02.321, indexed in Pubmed: 19264328.

67. Qi Y, Zhang F, Song Ge, et al. Cholinergic neuronal differentiation of bone marrow mesenchymal stem cells in rhesus monkeys. Sci China Life Sci. 2010; 53(5): 573-580, doi: 10.1007/ s11427-010-0009-4, indexed in Pubmed: 20596940.

68. Qin C, Lu Y, Wang K, et al. Transplantation of bone marrow mesenchymal stem cells improves cognitive deficits and alleviates neuropathology in animal models of Alzheimer's disease: a meta-analytic review on potential mechanisms. Transl Neurodegener. 2020; 9(1): 20, doi: 10.1186/s40035020-00199-x, indexed in Pubmed: 32460886.

69. Ramalho BD, Almeida FM, Sales CM, et al. Injection of bone marrow mesenchymal stem cells by intravenous or intraperitoneal routes is a viable alternative to spinal cord injury treatment in mice. Neural Regen Res. 2018; 13(6): 1046-1053, doi: 10.4103/1673-5374.233448, indexed in Pubmed: 29926832.

70. Rangan GK, Tesch GH. Quantification of renal pathology by image analysis. Nephrology (Carlton). 2007; 12(6): 553-558, doi: 10.1111/j.1440-1797.2007.00855.x, indexed in Pubmed: 17995580.

71. Reeve A, Simcox E, Turnbull D. Ageing and Parkinson's disease: why is advancing age the biggest risk factor? Ageing Res Rev. 2014; 14: 19-30, doi: 10.1016/j.arr.2014.01.004, indexed in Pubmed: 24503004.

72. Schliebs $R$, Arendt $T$. The cholinergic system in aging and neuronal degeneration. Behav Brain Res. 2011; 221(2): 555-563, doi: 10.1016/j.bbr.2010.11.058, indexed in Pubmed: 21145918.

73. Shekari A, Fahnestock M. Retrograde axonal transport of BDNF and proNGF diminishes with age in basal forebrain cholinergic neurons. Neurobiol Aging. 2019; 84: 131-140, doi: 10.1016/j.neurobiolaging.2019.07.018, indexed in Pubmed: 31574357.

74. Shen J, Tsai YT, Dimarco NM, et al. Transplantation of mesenchymal stem cells from young donors delays aging in mice. Sci Rep. 2011; 1: 67, doi: 10.1038/srep00067, indexed in Pubmed: 22355586.

75. Sikora E, Bielak-Zmijewska A, Dudkowska M, et al. Cellular senescence in brain aging. Front Aging Neurosci. 2021; 13: 646924, doi: 10.3389/fnagi.2021.646924, indexed in Pubmed: 33732142 .

76. Simpson JE, Wharton SB, Cooper J, et al. Alterations of the blood-brain barrier in cerebral white matter lesions in the ageing brain. Neurosci Lett. 2010; 486(3): 246-251, doi: 10.1016/j.neulet.2010.09.063, indexed in Pubmed: 20887772.

77. Stepanichev M, Nedogreeva O, Gulyaeva N. Cholinergic degeneration in early stages of Alzheimer's disease: loss of cholinergic phenotype or loss of cells? Alzheimers Dement Cogn Neurol. 2017; 1(2), doi: 10.15761/ adcn. 1000110.

78. Sun C, Shao J, Su Le, et al. Cholinergic neuron-like cells derived from bone marrow stromal cells induced by tricyclodecane-9-yl-xanthogenate promote functional recovery and neural protection after spinal cord injury. Cell Transplant. 2013; 22(6): 961-975, doi: 10.3727/096368912X657413, indexed in Pubmed: 23031841.

79. Tapia-Arancibia L, Aliaga E, Silhol M, et al. New insights into brain BDNF function in normal aging and Alzheimer dis- 
ease. Brain Res Rev. 2008; 59(1): 201-220, doi: 10.1016/j. brainresrev.2008.07.007, indexed in Pubmed: 18708092.

80. Tropel P, Platet N, Platel JC, et al. Functional neuronal differentiation of bone marrow-derived mesenchymal stem cells. Stem Cells. 2006; 24(12): 2868-2876, doi: 10.1634/ stemcells.2005-0636, indexed in Pubmed: 16902198.

81. Utkin YN. Aging affects nicotinic acetylcholine receptors in brain. Cent Nerv Syst Agents Med Chem. 2019; 19(2): 119-124, doi: 10.2174/1871524919666190320102834, indexed in Pubmed: 30894113.

82. Vallianatou T, Shariatgorji M, Nilsson A, et al. Molecular imaging identifies age-related attenuation of acetylcholine in retrosplenial cortex in response to acetylcholinesterase inhibition. Neuropsychopharmacology. 2019; 44(12): 2091-2098, doi: 10.1038/s41386-019-0397-5, indexed in Pubmed: 31009936.

83. Voigt RM, Raeisi S, Yang J, et al. Systemic brain derived neurotrophic factor but not intestinal barrier integrity is associated with cognitive decline and incident Alzheimer's disease. PLoS One. 2021; 16(3): e0240342, doi: 10.1371/ journal.pone.0240342, indexed in Pubmed: 33661922.

84. Volkman R, Offen D. Concise review: mesenchymal stem cells in neurodegenerative diseases. Stem Cells. 2017; 35(8): 1867-1880, doi: 10.1002/stem.2651, indexed in Pubmed: 28589621.

85. Wang X, Ma S, Yang Bo, et al. Resveratrol promotes hUC-MSCs engraftment and neural repair in a mouse model of Alzheimer's disease. Behav Brain Res. 2018; 339: 297-304, doi: 10.1016/j.bbr.2017.10.032, indexed in Pubmed: 29102593.

86. Wilkins $A$, Kemp $K$, Ginty $M$, et al. Human bone marrow-derived mesenchymal stem cells secrete brain-derived neurotrophic factor which promotes neuronal survival in vitro. Stem Cell Res. 2009; 3(1): 63-70, doi: 10.1016/j. scr.2009.02.006, indexed in Pubmed: 19411199.

87. Wills ED. Evaluation of lipid peroxidation in lipids and biologicalmembranes. In: Snell K, Mullock B (eds.), Biochemical toxicology: a practicalapproach. Oxford, London 1987.
88. Wu QY, Li J, Feng ZT, et al. Bone marrow stromal cells of transgenic mice can improve the cognitive ability of an Alzheimer's disease rat model. Neurosci Lett. 2007; 417(3): 281-285, doi: 10.1016/j.neulet.2007.02.092, indexed in Pubmed: 17412501.

89. Yi TG, Cho YK, Lee HJ, et al. A novel immunomodulatory mechanism dependent on acetylcholine secreted by human bone marrow-derived mesenchymal stem cells. Int J Stem Cells. 2019; 12(2): 315-330, doi: 10.15283/ ijsc18098, indexed in Pubmed: 31242717.

90. Yun HM, Kim HS, Park KR, et al. Placenta-derived mesenchymal stem cells improve memory dysfunction in an A 1 1-42-infused mouse model of Alzheimer's disease. Cell Death Dis. 2013; 4: e958, doi: 10.1038/cddis.2013.490, indexed in Pubmed: 24336078.

91. Zappa Villar MF, Lehmann M, García MG, et al. Mesenchymal stem cell therapy improves spatial memory and hippocampal structure in aging rats. Behav Brain Res. 2019; 374: 111887, doi: 10.1016/j.bbr.2019.04.001, indexed in Pubmed: 30951751.

92. Zhang XM, Ouyang YJ, Yu BQ, et al. Therapeutic potential of dental pulp stem cell transplantation in a rat model of Alzheimer's disease. Neural Regen Res. 2021; 16(5): 893-898, doi: 10.4103/1673-5374.297088, indexed in Pubmed: 33229725.

93. Zhou G, Xiong W, Zhang X, et al. Retrieval of consolidated spatial memory in the water maze is correlated with expression of $p C R E B$ and egr 1 in the hippocampus of aged mice. Dement Geriatr Cogn Dis Extra. 2013; 3(1): 39-47, doi: 10.1159/000348349, indexed in Pubmed: 23569457.

94. Zia A, Pourbagher-Shahri AM, Farkhondeh T, et al. Molecular and cellular pathways contributing to brain aging. Behav Brain Funct. 2021; 17(1): 6, doi: 10.1186/s12993021-00179-9, indexed in Pubmed: 34118939.

95. Zilka N, Zilkova M, Kazmerova Z, et al. Mesenchymal stem cells rescue the Alzheimer's disease cell model from cell death induced by misfolded truncated tau. Neuroscience. 2011; 193: 330-337, doi: 10.1016/j.neuroscience.2011.06.088, indexed in Pubmed: 21763758. 